\title{
Structural and mechanistic aspects influencing the ADAM10-mediated shedding of the prion protein
}

\author{
Luise Linsenmeier', Behnam Mohammadi', Sebastian Wetzel2, Berta Puig ', Walker S. Jackson³, \\ Alexander Hartmann ${ }^{1}$, Keiji Uchiyama ${ }^{4}$, Suehiro Sakaguchi ${ }^{4}$, Kristina Endres ${ }^{5}$, Jörg Tatzelt ${ }^{6}$, Paul Saftig ${ }^{2}$, \\ Markus Glatzel $^{1 *}$ and Hermann C. Altmeppen ${ }^{1 *}$
}

\begin{abstract}
Background: Proteolytic processing of the prion protein $\left(\mathrm{PrP}^{\mathrm{C}}\right)$ by endogenous proteases generates bioactive membrane-bound and soluble fragments which may help to explain the pleiotropic roles of this protein in the nervous system and in brain diseases. Shedding of almost full-length $\operatorname{PrP}^{C}$ into the extracellular space by the metalloprotease ADAM10 is of peculiar relevance since soluble PrP stimulates axonal outgrowth and is protective in neurodegenerative conditions such as Alzheimer's and prion disease. However, molecular determinates and mechanisms regulating the shedding of PrP are entirely unknown.

Methods: We produced an antibody recognizing the neo-epitope of shed PrP generated by ADAM10 in biological samples and used it to study structural and mechanistic aspects affecting the shedding. For this, we investigated genetically modified cellular and murine models by biochemical and morphological approaches.

Results: We show that the novel antibody specifically detects shed PrP in cell culture supernatants and murine brain. We demonstrate that ADAM10 is the exclusive sheddase of $\operatorname{PrP}^{C}$ in the nervous system and reveal that the glycosylation state and type of membrane-anchorage of $\operatorname{PrP}^{C}$ severely affect its shedding. Furthermore, we provide evidence that PrP shedding can be modulated by pharmacological inhibition and stimulation and present data suggesting that shedding is a relevant part of a compensatory network ensuring $\operatorname{PrP}^{C}$ homeostasis of the cell.

Conclusions: With the new antibody, our study introduces a new tool to reliably investigate PrP-shedding. In addition, this study provides novel and important insight into the regulation of this cleavage event, which is likely to be relevant for diagnostic and therapeutic approaches even beyond neurodegeneration.
\end{abstract}

Keywords: ADAM10, Antibody, Exosomes, Glycosylation, Membrane anchor, Neurodegeneration, Prion protein, Proteolytic cleavage, Shedding

\section{Background}

Proteolytic processing is an essential regulator of protein function and differs from many other posttranslational modifications by its irreversible character. As exemplified decades ago in the case of prohormones (such as the proopiomelanocortin [1]), differential or subsequent cleavages by endogenous proteases produce fragments with intrinsic biological functions, differing from the

\footnotetext{
* Correspondence: m.glatzel@uke.de; h.altmeppen@uke.de

${ }^{1}$ Institute of Neuropathology, University Medical Center Hamburg-Eppendorf (UKE), Hamburg, Germany

Full list of author information is available at the end of the article
}

ones of the larger precursors. This concept may also help in understanding and explaining the biology of other "multifunctional" proteins, i.e. proteins with more than just one particular function ascribed to them.

One of these proteins is the cellular prion protein $\left(\operatorname{Pr} \mathrm{P}^{\mathrm{C}}\right)$, for which a multitude of physiological functions has been suggested in different tissues, cells and experimental settings $[2,3]$, even though not in each case without controversy or questionable reproducibility $[4,5]$. For instance, $\operatorname{PrP}^{\mathrm{C}}$ has been linked to developmental processes [6,7], cell adhesion [8,9], neurite outgrowth, axon guidance and synapse formation [10-14], as well as 
to neuroprotection [15-17] and regulation of the circadian rhythm [18]. Among the currently best characterized functions are its contributions to myelin maintenance [4, 19-21] and cellular homeostasis of divalent ions [22, 23] as well as its involvement in signaling events [24-26].

Too many functional implications for just one protein? Not necessarily. While transient interactions of $\operatorname{PrP}^{\mathrm{C}}$ with alternating binding partners in different cellular locations may partially account for this functional diversity [5, 27], so might its proteolytic processing [28]. In fact, different highly conserved cleavage events occur constitutively on a relevant fraction of $\operatorname{PrP}^{C}$ [29-31], yet scientists are just starting to understand their biological relevance.

In contrast to some of the suggested physiological functions, the relevance of $\operatorname{PrP}^{\mathrm{C}}$ in neurodegenerative proteinopathies is widely accepted. First and foremost, it is the essential substrate for the process of templated misfolding underlying fatal and transmissible prion diseases, such as Creutzfeldt-Jakob disease in humans or BSE in cattle [32-34]. Once having adopted its pathogenic conformation $\left(\mathrm{PrP}^{\mathrm{Sc}}\right)$, the prion protein is the key component of the infectious particles termed prions [32, 35-37]. Second, binding of toxic oligomeric protein species, such as $\operatorname{PrP}^{\mathrm{Sc}}$ (in prion diseases [38]), $\mathrm{A} \beta$ (in Alzheimer's disease [39-42]) or $\alpha$-synuclein (in Parkinson's disease $[43,44])$, to $\operatorname{PrP}^{C}$ at the neuronal surface results in neurotoxic signaling. As for the physiological functions, increasing evidence suggests that proteolytic cleavages also impact on these pathogenic roles of the prion protein $[28,45,46]$.

Here, we focus on the most membrane-proximate cleavage of $\operatorname{PrP}^{\mathrm{C}}$, i.e. its shedding from the neuronal surface and release into the extracellular space by the metalloprotease ADAM10 [47, 48]. This cleavage not only regulates membrane levels of $\operatorname{PrP}^{\mathrm{C}}$ and, thus, $\operatorname{PrP}^{\mathrm{C}}$ related functions at the neuronal surface [28]. The resulting soluble fragment, shed PrP, likely has intrinsic functions as supported by studies using (recombinant) anchorless analogues, that showed beneficial effects with regard to axon outgrowth and synapse formation [13, 14] or neuroprotection [15, 49]. Focusing on neurodegeneration, we have recently shown a significant impact on the course of prion disease in mice by conditional depletion of the sheddase ADAM10 [50,51], as have others by overexpression of exogenous ADAM10 [52] or by transgenic expression of anchorless versions of $\operatorname{PrP}[53,54]$. Moreover, by reducing membrane-bound $\operatorname{PrP}^{\mathrm{C}}$ as a receptor and by producing anchorless PrP, which can block and detoxify $A \beta$ and other harmful protein species in the extracellular space [55-58], shedding may also have a protective role in other, more frequent proteinopathies [45].
Surprisingly, shed PrP has recently been associated with the development of specific tumours in the nervous system, where it correlates with increased cancer cell proliferation [59]. In addition, a recent report shows critical involvement of shed $\operatorname{PrP}$ in the neuropathogenesis of HIV/AIDS by recruiting monocytes and aggravating the inflammatory response and the associated cognitive impairment [60].

Thus, given that shedding of $\operatorname{PrP}^{\mathrm{C}}$ might provide a promising and potent target for therapy of various pathological conditions, a deeper mechanistic understanding and knowledge of factors influencing this cleavage is required. Here, we first introduce and characterize a novel antibody detecting shed PrP with high specificity and sensitivity. Using this tool, we investigate different structural (i.e. glycosylation state and membrane anchorage) and mechanistic aspects in vitro and in vivo for how they impact on this relevant proteolytic event. Finally, we show that shedding is part of a compensatory cellular network regulating $\operatorname{PrP}^{\mathrm{C}}$ homeostasis.

\section{Methods}

\section{Plasmids}

The following constructs were used for transient transfection of cells. Detailed descriptions of the constructs can be found in the corresponding references: PrP-WT, $\operatorname{PrP}^{C}$ glycomutants PrP-G1, PrP-G2, PrP-G3 and anchormutant PrP ${ }^{\text {GPI-Thy1 }}$ [61], PrP-TM (PrP-CD4 [62, 63]). All $\operatorname{PrP}$ constructs contained the 3F4 tag [64]. The Nterminally truncated $\mathrm{PrP}-\mathrm{C} 1$ construct was cloned from the plasmid pcDNA3.1(+)/Zeo containing the murine Prnp gene. The sequence coding for the N-terminal part of $\operatorname{PrP}^{\mathrm{C}}$ (aa23-110) was deleted by use of the restriction enzymes $\mathrm{XbaI}$ and HindIII and the resulting construct ( $\triangle \mathrm{aa} 23-110$; i.e. PrP-C1) was verified by DNA sequencing.

\section{Antibody production}

The $\mathrm{sPrP}^{\mathrm{G} 228}$ antibody for the specific detection of shed $\operatorname{PrP}$ was generated by use of an anti-peptide approach and the classical 87-day polyclonal protocol (Eurogentec, Belgium). Briefly, based on the sequence information of murine $\operatorname{PrP}^{\mathrm{C}}$ and previous determination of the cleavage site for ADAM10 [47], a recombinant peptide $\mathrm{NH}_{2}$-CQAYYDG-COOH (in which G-COOH represents G228 as the new C-terminus of shed $\operatorname{PrP}$ exposed after cleavage (Fig. 1a)) was produced and $\mathrm{N}$-terminally coupled to Megathura crenulata keyhole limpet hemocyanin (KLH) as carrier protein. This peptide was used as immunogen and injected into rabbit at days $0,14,28$ and 56 of the programme. Bleedings were done at days 0,38 and 66 to investigate the success of the immunization process by standardized ELISA tests. Animals were sacrificed and final bleeds were obtained at day 87. Standardized 


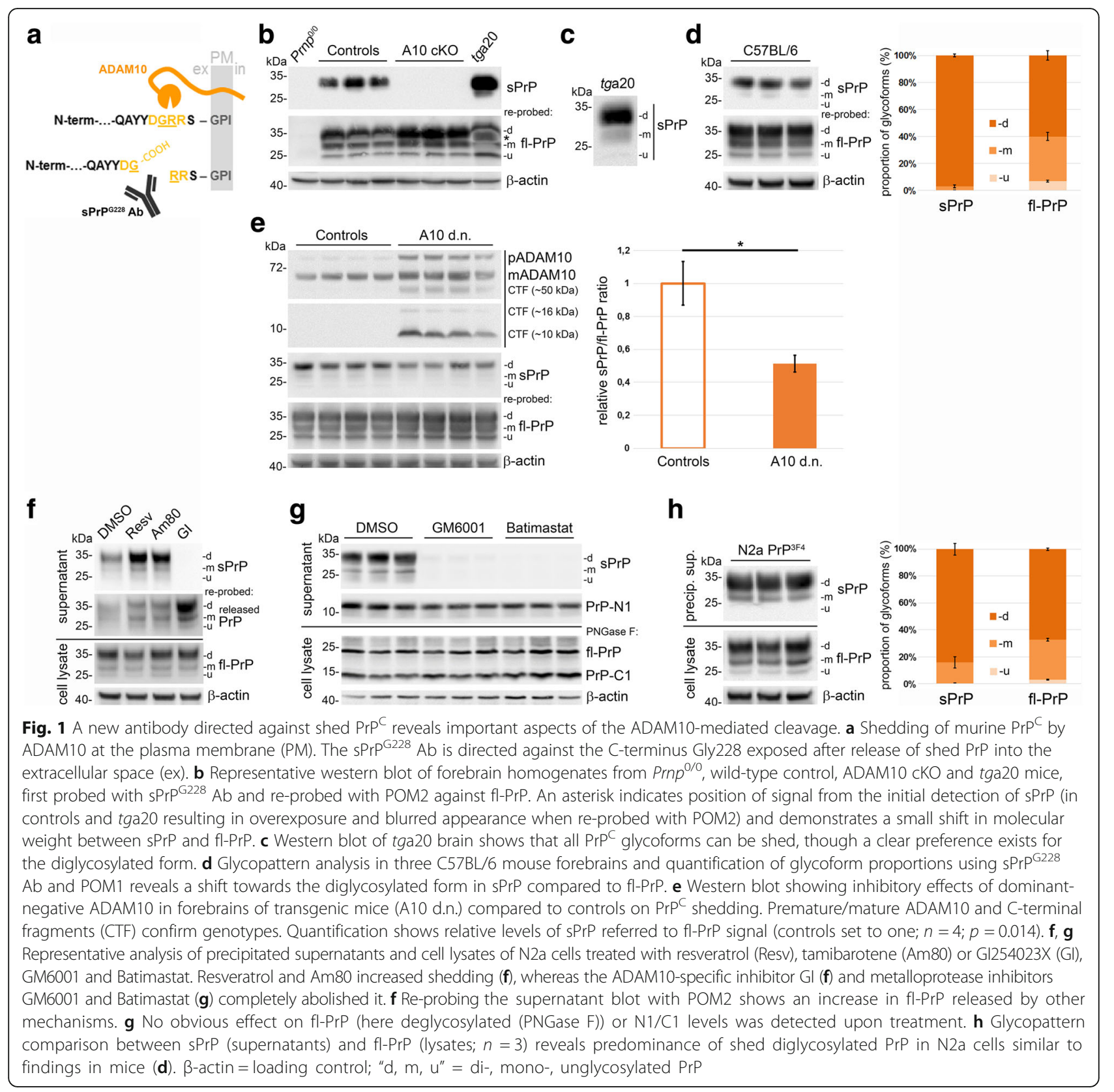

quality measures and affinity purification were performed at Eurogentec. Importantly, a second peptide $\left(\mathrm{NH}_{2}-\mathrm{C}-\mathrm{KESQAYYDGRRS-COOH}\right)$ mimicking the Cterminus of fl-PrP (without the GPI anchor) was produced, coupled to a resin and served as a "negative control" to eliminate all antibodies from the polyclonal serum that would otherwise bind to fl-PrP.

\section{Rodent brain samples}

Use of animal material in this study was in strict compliance with the Guide for the Care and Use of Laboratory Animals and ethics guidelines of the responsible local authorities. Frozen forebrain samples from wild-type
C57BL/6, prion protein deficient $\left(\operatorname{Prnp}^{0 / 0}[65]\right)$, prion protein overexpressing (tga20 [66]) mice as well as from mice with conditional knockout of ADAM10 in forebrain neurons (A10 cKO and wild-type littermate controls [67]), with transgenic overexpression of dominant negative ADAM10 (A10 d.n. and wild-type controls [68]), with depletion of sortilin-1 (Sort1 KO and wildtype controls [69]) or with a knock-in of 3F4-tagged $\operatorname{PrP}^{\mathrm{C}}\left(\operatorname{PrP}^{3 \mathrm{~F} 4} \mathrm{KI}\right.$ and controls; both had a 192S4 background [70]), and from a rat and a rabbit were used to prepare $10 \%(w / v)$ homogenates in RIPA buffer (50 mM Tris- $\mathrm{HCl}$ pH 8, $150 \mathrm{mM} \mathrm{NaCl}, 1 \% \mathrm{NP}-40,0.5 \%$ Na-Deoxycholate, $0.1 \%$ SDS) freshly supplemented with 
Complete EDTA-free protease (PI) and PhosStop phosphatase inhibitor cocktails (Roche) on ice. Samples were homogenized with 30 strokes using a dounce homogenizer and incubated on ice for $20 \mathrm{~min}$, shortly vortexed and incubated for another $20 \mathrm{~min}$ before centrifugation at $12,000 \mathrm{~g}$ at $4{ }^{\circ} \mathrm{C}$ for $12 \mathrm{~min}$. Total protein content was assessed by Bradford assay (BioRad). Supernatants were either further processed for SDS-PAGE or stored at $-80^{\circ} \mathrm{C}$.

\section{Cell culture, transfection and treatments}

Murine neuroblastoma cells (N2a) and mouse embryonic fibroblasts (MEF; [71]) were maintained at $37{ }^{\circ} \mathrm{C}$ under an atmosphere of $5 \% \mathrm{CO}_{2}$ in Dulbecco's modified Eagle's medium (DMEM; Thermo Fisher Scientific) supplemented with $10 \%$ fetal bovine serum (FBS; Thermo Scientific Fisher). N2a PrP-KO cells were generated using the TALEN approach and characterized in detail before [72]. N2a PrP-KO cells were transfected using Lipofectamine 2000 (Thermo Fisher Scientific) following the manufacturer's instructions. For stable overexpression of $\mathrm{PrP}^{3 \mathrm{~F} 4}$ in $\mathrm{N} 2 \mathrm{a}$ PrP-KO (used for the glycopattern analysis shown in Fig. 1h) cells were kept for 3 weeks in selection media (Zeocin $400 \mu \mathrm{g} / \mathrm{ml}$; Thermo Fisher Scientific) and single resistant clones were selected for amplification.

Treatments of cells were performed by adding the following compounds (and concentrations) to the cell culture media: Resveratrol $(20 \mu \mathrm{M})$, Tamibarotene/Am80 $(1 \mu \mathrm{M}), \mathrm{GI} 254023 \mathrm{X}(3 \mu \mathrm{M})$, Tunicamycin $(2.5 \mu \mathrm{g} / \mathrm{ml})$, Swainsonine $(5 \mu \mathrm{g} / \mathrm{ml})$, Leupeptin $(200 \mu \mathrm{g} / \mathrm{ml})$. All compounds were purchased from Merck. These treatments were carried out in 6-well plates with $1 \mathrm{ml}$ OptiMEM for $18 \mathrm{~h}$ overnight. In the case of Tunicamycin and Swainsonine cells were pretreated for $8 \mathrm{~h}$. Treatment with GM6001 $(25 \mu \mathrm{M})$ or Batimastat $(10 \mu \mathrm{M})$ was for $10 \mathrm{~h}$.

\section{Treatment of cells with PI-PLC}

Two days post-transfection cells (grown in 6-well plate format) were incubated with $0.5 \mathrm{U} / \mathrm{ml}$ Phospholipase $\mathrm{C}$ (PI-PLC; Sigma-Aldrich) in $1 \mathrm{ml}$ OptiMEM for $2 \mathrm{~h}$ at $37{ }^{\circ} \mathrm{C}, 5 \% \mathrm{CO}_{2}$ in order to cleave GPI-anchor structures and release GPI-anchored proteins from the cellular surface. Supernatants were subsequently harvested and further processed while cells were lysed as described below.

\section{PNGase $\mathrm{F}$ and Endo $\mathrm{H}$ digestion}

For removal as well as for investigations on processing and maturation of $\mathrm{N}$-linked glycans attached to $\operatorname{PrP}^{\mathrm{C}}$, cell lysates and/or supernatants were digested with either PNGase F or Endo H (New England Biolabs) according to the manufacturer's protocols.
Sample preparation, TCA precipitation, cell surface biotinylation assay, SDS-PAGE and western blot analysis N2a cells were washed with PBS and lysed with RIPA buffer, incubated on ice for $15 \mathrm{~min}$ before centrifugation at $12,000 \mathrm{~g}$ for $12 \mathrm{~min}$ at $4{ }^{\circ} \mathrm{C}$. The protein content of the resulting supernatant was determined by Bradford assay. Prior to SDS-PAGE, cell lysates or brain homogenates (see above) were mixed with $4 \times$ loading buffer (including $\beta$-mercaptoethanol) and denatured for $6 \mathrm{~min}$ at $96^{\circ} \mathrm{C}$.

For the analysis of cell culture supernatants, experiments were carried out with serum-free media (OptiMEM). Supernatants were precipitated with trichloroacetic acid (TCA). For this, supernatants were collected and immediately incubated with already dissolved protease inhibitor cocktail, cleared from dead cells and debris by mild centrifugations at $500 \mathrm{~g}$ and $5.000 \mathrm{~g}$ for $5 \mathrm{~min}$ each. 1/100 volume of $2 \%$ sodium deoxycholate $(\mathrm{NaDOC})$ was then added and each sample was shortly vortexed. After $30 \mathrm{~min}$ incubation on ice, samples were mixed with $1 / 10$ volume of $100 \%$ TCA and again incubated for $30 \mathrm{~min}$ on ice. After centrifugation at $15,000 \mathrm{~g}$ for $15 \mathrm{~min}$ at $4{ }^{\circ} \mathrm{C}$, the supernatant was aspirated, and the air-dried pellet was dissolved in $1 \times$ loading buffer and boiled for $6 \mathrm{~min}$ at $96^{\circ} \mathrm{C}$.

For labelling and purification of proteins at the cell surface, a surface biotinylation assay was performed as described earlier [50] prior to cell lysis.

For SDS-PAGE, denatured samples were loaded on either precast Nu-PAGE 4-12\% Bis-Tris protein gels (Thermo Fisher Scientific) or self-made $10 \%$ or $12 \%$ SDS-gels. After electrophoretic separation, proteins were transferred to nitrocellulose membranes (BioRad) by wet-blotting and membranes were subsequently blocked for $1 \mathrm{~h}$ with $5 \%$ skimmed dry milk dissolved in TBS-T (containing 0.1\% Tween-20) and incubated with primary antibody diluted in $5 \%$ skimmed dry milk in TBS-T overnight at $4{ }^{\circ} \mathrm{C}$ on a shaking platform. For detection of full length $\operatorname{PrP}^{\mathrm{C}}(\mathrm{fl}-\mathrm{PrP})$, mouse monoclonal antibodies POM1 $(1 \mu \mathrm{g} / \mathrm{ml})$, POM2 (0. $6 \mu \mathrm{g} / \mathrm{ml}$ ) [73] or, in the case of the sortilin-1 knockout mouse brains (Fig. 5j), SAF61 (0.2 $\mathrm{\mu g} / \mathrm{ml}$; Bertin Pharma) were used. Proteolytically shed $\operatorname{PrP}^{\mathrm{C}}$ was detected with our new rabbit polyclonal $\operatorname{sPrP}^{\mathrm{G} 228}$ antibody $(0.2 \mu \mathrm{g} / \mathrm{ml})$ characterized in detail herein. Moreover, we used antiADAM10 $(0.4 \mu \mathrm{g} / \mathrm{ml} ;$ abcam $)$, anti-mouse $\beta$-amyloid antibody for detection of sAPPa $(1 \mu \mathrm{g} / \mathrm{ml}$; BioLegend), anti-actin antibody clone C4 (MAB1501, 1:1000; Merck) and anti-Flotillin-1 clone $18(0.25 \mu \mathrm{g} / \mathrm{ml}$; BD Biosciences). Membranes were subsequently washed with TBS-T and incubated for $1 \mathrm{~h}$ with respective HRP-conjugated secondary antibodies and subsequently washed $6 \times$ with TBS-T. After incubation with Pierce ECL Pico or Super Signal West Femto substrate (Thermo Fisher Scientific), chemiluminescence was detected with a ChemiDoc imaging station (BioRad) and densitometrically quantified using Image Studio Lite software version 5.2 (LI-COR). 


\section{Immunofluorescence staining of surface proteins and microscopy}

N2a cells were grown on glass coverslips. After washing with PBS, living cells were incubated for $20 \mathrm{~min}$ on ice (to avoid endocytosis) with the primary antibody dissolved in $2 \%$ BSA/PBS. Surface $\operatorname{PrP}^{C}$ was detected with POM1 antibody $(10 \mu \mathrm{g} / \mathrm{ml})$. After several washes with PBS, cells were incubated with suitable secondary antibodies for $20 \mathrm{~min}$ on ice, subsequently fixed in $4 \%$ paraformaldehyde for $20 \mathrm{~min}$ at room temperature and mounted on glass slides with DAPI Fluoromount G (Southern Biotech). Analysis was performed using a TCS SP5 confocal microscope (Leica).

\section{Histological and immunohistochemical stainings}

Sampling, formalin fixation, paraffin embedding, hematoxilin and eosin (H\&E) staining as well as immunostaining with anti-prion protein antibody SAF84 (Caiman Chemical) of murine brain samples has been described earlier [50]. Immunostaining of shed PrP was likewise performed in one run using a Benchmark XT machine (Ventana) to allow for best comparability. In brief, deparaffinated brain sections were boiled for $1 \mathrm{~h}$ in citrate buffer (CC1 Cell Conditioning Solution, Ventana) for antigen retrieval and then incubated for $1 \mathrm{~h}$ with the sPrP $^{\mathrm{G} 228}$ primary antibody $(7 \mu \mathrm{g} / \mathrm{ml}$; in antibody diluent solution (Zytomed) with 5\% goat serum). Detection with anti-rabbit secondary antibody (Nichirei Biosciences) and Ultra View Universal DAB Detection kit (Ventana), as well as blue counterstaining were performed by the machine following standardized protocols.

\section{Exosome isolation and nanoparticle tracking analysis}

N2a cells were cultured in OptiMEM for $18 \mathrm{~h}$. For the harvest of extracellular vesicles (here further referred to as exosomes), cell culture supernatants were first complemented with PI and centrifuged for $10 \mathrm{~min}$ at $1000 \mathrm{~g}$ and further at $7500 \mathrm{~g}$ for $15 \mathrm{~min}$ at $4{ }^{\circ} \mathrm{C}$, followed by filtration through a $22 \mu \mathrm{m}$ membrane to clear it from dead cells and debris. Exosomes were then pelleted by ultracentrifugation at $100,000 \mathrm{~g}$ for $70 \mathrm{~min}$ at $4{ }^{\circ} \mathrm{C}$ in an $\mathrm{Op}$ tima L-100 XP using a SW40Ti rotor (Beckman Coulter, Inc.) and subsequently resuspended in PBS containing PI. For quantification and characterization, a NanoSight LM14 (Malvern Instruments) equipped with a $638 \mathrm{~nm}$ laser and a Marlin F033B IRF camera (Allied Vision Technologies) was used. For each sample, 10 videos of $10 \mathrm{~s}$ length were recorded with a camera intensity setting of 16 and analysed to assess average size and concentration of exosomes using the batch processing function of the software. For normalized western blot analysis, $5 \times 10^{10}$ exosomes per sample were used.

\section{Statistical analysis}

For experiments using mouse brain samples, $n$ refers to the number of biological samples (i.e. mice) per experimental group. For cell culture-based data, $n$ stands for the number of independent experiments. Statistical comparison of western blot quantifications was performed using Student's t-test and significance was considered with $p$ values as follows: ${ }^{*} p<0.05,{ }^{* *} p<0.005,{ }^{* * * *} p<0.001$.

\section{Results}

A novel antibody specifically detects shed PrP and reveals important insight into the ADAM10-mediated shedding of $\mathrm{PrP}^{\mathrm{C}}$ in mice and cells

ADAM10 is the relevant sheddase of $\operatorname{PrP}^{\mathrm{C}}$ releasing a soluble form (shed PrP, sPrP) from the plasma membrane [47, 48]. Since membrane-bound full length (fl) $\mathrm{PrP}^{\mathrm{C}}$ and its shed form only differ in three amino acids (murine sequence) and the GPI-anchor, it is hard to reliably discriminate between both in most approaches. Based on available sequence information and the previous identification of the cleavage site for ADAM10 [47], we therefore generated an antibody specific for $\mathrm{sPrP}\left(\mathrm{sPrP}^{\mathrm{G} 228}\right)$ being directed against the newly generated carboxy-terminus at Glycine 228 (G228) exposed after cleavage (Fig. 1a).

To characterize this antibody in detail, we analyzed forebrain homogenates of age-matched Prnp ${ }^{0 / 0}$ mice (as negative control), recently described mice with neuronspecific (CamKII $\alpha$-driven) depletion of ADAM10 (A10 cKO; to control for specificity) as well as wild-type littermate controls, and $\mathrm{PrP}^{\mathrm{C}}$-overexpressing tga20 mice (as positive controls) by western blot. As expected, detection with our new antibody consistently revealed no signal in $\operatorname{Prnp}^{0 / 0}$ samples, basal levels in wild-type mice and strongly increased signal intensity in tga20 mice (Fig. 1b). Though we expected significantly reduced levels of shed PrP in A10 cKO mice, to our surprise we could not detect any signal in these samples. Besides supporting the specificity of the antibody, this indicates that no other cell types or proteases contribute to this cleavage in brain. Re-probing the same blot with an antibody against fl-PrP revealed an increase in total $\operatorname{PrP}^{C}$ levels in A10 cKO mouse brains (Fig. 1b), a finding that has been made earlier and can be attributed to the lack of shedding [50]. Moreover, while this blotting strategy demonstrated the overlapping banding pattern (as well as the masking of sPrP signals by excess amounts of flPrP using common PrP antibodies), it also revealed a small shift in the molecular weight of sPrP corresponding to the lack of three amino acids and the GPI-anchor (Fig. $1 \mathrm{~b}$ and Additional file 1). We also investigated the species specificity of the new antibody using mouse, rat and rabbit brain samples. As expected for the different C-terminal $\operatorname{PrP}^{C}$ sequences, the $\operatorname{sPrP}^{\mathrm{G} 228}$ antibody only 
detected $\mathrm{sPrP}$ in brain homogenates of mice and rat (Additional file 2).

Though not being in the focus of this study, we were also interested in the applicability of the antibody in morphological analyses and performed immunohistochemical staining of paraffin-embedded mouse brain sections. As exemplified for the hippocampal area in Additional file 3, no signal was obtained in a $\operatorname{Prnp}{ }^{0 / 0}$ mouse, whereas a diffuse staining was found in wild-type and, with higher intensity, in tga 20 brain as could be expected for a soluble fragment distributed in the brain parenchyma.

Although, structurally, all three glycoforms of $\operatorname{PrP}^{\mathrm{C}}$ can be shed (as demonstrated in tga20 brain (Fig. 1c)), a strong predominance of the diglycosylated form of $\mathrm{sPrP}$ was obvious in all of our biochemical analyses. To investigate this in more detail, we analyzed the glycopattern of sPrP compared to cell-associated fl-PrP in brain homogenates of wild-type mice (Fig. 1d) and found a clear shift and a drastic increase in the proportion of diglycosylated sPrP (mean: $97 \pm 1 \%$; compared to $60 \pm 4 \%$ for fl-PrP; $n=3 ; \pm$ SD) with only little mono- (3 $\pm 1 \%$; fl-PrP: $33 \pm 3 \%$ ) and almost no unglycosylated $\mathrm{sPrP}$ $(0.07 \pm 0.03 \%$; fl-PrP: $6.8 \pm 0.8 \%)$.

As a model for downregulation of ADAM10-mediated cleavage events, we investigated PrP shedding in forebrains of mice overexpressing a dominant negative form of ADAM10 (A10 d.n.) in addition to the endogenous protease [68] (Fig. 1e). When referring the $\mathrm{sPrP}$ to the respective fl-PrP signal, we found a $\sim 50 \%$ reduction (mean $\operatorname{sPrP} / \mathrm{fl}-\operatorname{PrP}$ ratio: $0.51 \pm 0.05 ; n=4 ; \pm$ SEM) in A10 d.n. mice compared to matched controls (set to 1 . $00 \pm 0.13)$.

Since for main parts of this study we used N2a cells transfected with murine versions of $\operatorname{PrP}^{\mathrm{C}}$ containing the 3F4 tag in the middle of the protein sequence, we first had to show that this modification does not influence the shedding event. This is even more important as it is known, that the course of prion diseases is altered by this tag [70, 74]. We therefore decided to investigate shedding in the best possible model, i.e. in $\operatorname{PrP}^{3 \mathrm{~F} 4}$ knockin (KI) mice expressing levels of 3F4-tagged PrP identical to $\operatorname{PrP}^{\mathrm{C}}$ levels in wild-type mice (Additional file 1) [70]. No significant differences in $\operatorname{sPrP}$ levels were observed between controls (set to $1.00 \pm 0.23 ; \mathrm{n}=3 ; \pm \mathrm{SD}$ ) and $\mathrm{PrP}^{3 \mathrm{~F} 4} \mathrm{KI}$ mice $(0.85 \pm 0.12)$ thus ruling out an impact of this modification on PrP shedding as could be expected from its intramolecular distance to the membrane-proximate shedding site.

We next employed the new antibody in cell culturebased experiments. Given that manipulation of $\operatorname{PrP}^{\mathrm{C}}$ shedding may become a therapeutic option in different pathologies, we investigated how pharmacological stimulation and inhibition of ADAM10 affect $\mathrm{sPrP}$ production in N2a cells (Fig. 1f,g). Among others, the stilbenoid resveratrol and the synthetic retinoid tamibarotene (Am80) have been successfully used to increase ADAM10-mediated cleavage events [75, 76]. We also found elevated levels of sPrP in supernatants of $\mathrm{N} 2 \mathrm{a}$ cells treated with these substances compared to solvent-treated controls (Fig. 1f). In contrast, shedding was abolished upon treatment with the ADAM10selective inhibitor GI254023X (GI) [77]. Of note, upon re-probing the "supernatant blot" with another PrP antibody (POM2), a strong signal was obtained under GItreatment indicative of a release of fl-PrP by alternative routes when shedding is blocked (as discussed later). Fittingly, cell-associated $\mathrm{PrP}^{\mathrm{C}}$ levels (in lysates) remained rather unaffected by the different treatments further supporting existence of compensatory mechanisms regulating $\operatorname{PrP}^{\mathrm{C}}$ homeostasis in $\mathrm{N} 2 \mathrm{a}$ cells (discussed later). We also assessed the metalloprotease inhibitors GM6001 and batimastat (Fig. 1g). These drugs likewise abolished the shedding of $\operatorname{PrP}^{C}$ at the cell surface yet did not significantly alter production of $\mathrm{N} 1$ and $\mathrm{C} 1$ fragments resulting from the $\alpha$-cleavage of $\operatorname{Pr} P^{C}$. There is controversy regarding the involvement of ADAMs in the $\alpha$-cleavage (reviewed in $[45,78]$ ). However, due to the lack of membrane permeability of the inhibitors used here, this finding cannot count as an argument against ADAMs as potential " $\alpha$-PrPases", given that $\alpha$-cleavage is thought to occur mainly within the secretory pathway [79]. Again, levels of cell-associated fl-PrP did not appear to be altered by these treatments.

Lastly, consistent with our findings in mouse brain (Fig. 1d), we also observed a changed glycopattern of sPrP compared to fl-PrP in N2a cells (Fig. 1h; diglycosylated: $84.2 \pm 4.4 \%(\mathrm{sPrP})$ vs. $67.4 \pm 0.9 \%$ (fl-PrP); monoglycosylated: $15.6 \pm 4.2 \%(\mathrm{sPrP})$ vs. $29.6 \pm 1.0 \%$ (fl-PrP); unglycosylated: $0.22 \pm 0.18 \%$ (sPrP) vs. $2.9 \pm 0.3 \%$ (fl$\operatorname{PrP}) ; n=3 ; \pm \mathrm{SD}$ ) though relatively more monoglycosylated $\mathrm{sPrP}$ is found in $\mathrm{N} 2 \mathrm{a}$ cells $(15.6 \pm 4.2 \%)$ than in brain ( $3 \pm 1 \%$; Fig. $1 d)$. To clarify whether our findings indicate a real preference for the shedding of diglycosylated $\operatorname{PrP}$ or rather reflect the availability of different glycoforms at the plasma membrane, we performed cell surface biotinylation and glycopattern analysis in N2a cells (Additional file 4). Though relatively more diglycosylated $\operatorname{PrP}$ is indeed available at the plasma membrane (compared to total PrP levels in cell lysates; Additional file 4B), our data still argues in favor of a preference for diglycosylated $\operatorname{PrP}$ given the strong predominance of this form among shed PrP (Fig. 1d, h). In summary, we have generated a sensitive and highly specific antibody to discriminate between shed and fl-PrP in mouse brains and cell culture supernatants. ADAM10 on neurons seems to be the dominant (if not exclusive) PrP sheddase. ADAM10-mediated shedding of $\operatorname{PrP}^{\mathrm{C}}$ can 
be modulated by various means, and our sheddingspecific antibody is a useful read-out tool for such experiments. Though all glycoforms can in principle be shed, diglycosylated PrP by far represents the major substrate for ADAM10.

\section{The glycosylation state impacts on PrP shedding}

Glycosylation of $\operatorname{PrP}^{\mathrm{C}}$ impacts on its biology and role in prion disease [62, 80-83]. Given the predominance of diglycosylated sPrP under normal conditions (Fig. 1), we wondered how shedding would be affected if only specific glycoforms of $\mathrm{PrP}^{\mathrm{C}}$ are present in cells. To this end, we transfected $\mathrm{PrP}^{\mathrm{C}}$-depleted N2a cells (PrP-KO; generated using the TALEN strategy and described earlier [72]) with either wild-type PrP or PrP glycomutants carrying a mutation in either the first (N180Q mutant; PrP-G1), the second (N196Q mutant; PrP-G2) or both (N180Q/N196Q mutant; PrP-G3) N-glycosylation sites and, thus, giving rise to mono- (G1 and G2) or unglycosylated $(\mathrm{G} 3) \operatorname{PrP}^{\mathrm{C}}$. Using these glycomutants, we could previously demonstrate a relevant impact of the $\mathrm{N}$-glycans on the sorting of $\operatorname{PrP}^{\mathrm{C}}$ in polarized cells [61]. Despite differences in transfection efficiencies, western blot analysis revealed the typical banding pattern for the glycomutants as observed for similar mutants in transgenic mice (Fig. 2a) [83]. Like fl-PrP, the membrane-attached $\mathrm{C} 1$ fragment resulting from $\alpha$ cleavage of $\operatorname{PrP}^{\mathrm{C}}$ also presents with a three-banding pattern with the diglycosylated $\mathrm{C} 1$ overlapping with unglycosylated fl-PrP. For a better characterization, deglycosylation was performed to only obtain unglycosylated $\mathrm{fl}-\mathrm{PrP}$ and $\mathrm{C} 1$ fragment and showed that all mutants undergo $\alpha$-cleavage (Fig. $2 b$ ). No effect was observed upon treatment of lysates with Endo $\mathrm{H}$ indicating a correct processing of the glycans and trafficking out of the ER and to the cellular surface for all transfected mutants (Fig. 2c). Immunofluorescence analysis of surface $\operatorname{PrP}^{\mathrm{C}}$ further supported a correct biosynthesis and showed that all mutants are readily expressed at the plasma membrane (Fig. 2f) confirming previous results in polarized MDCK cells [61]. Of note, analysis of sPrP in media supernatants revealed that not only fl-PrP but also the truncated $\mathrm{C} 1$ fragment can be shed for all glycoforms (Fig. 2d; deglycosylation of supernatants for confirmation of bands is shown in Fig. 2g). Quantification (Fig. 2e) of sPrP referred to total PrP (to correct for different transfection efficiencies) showed a moderate decrease in $\mathrm{SPrP}$ for the monoglycosylated mutants, yet a significant reduction to $\sim 50 \%$ was observed for the unglycosylated PrP-G3 (mean: $0.49 \pm 0.11$ compared to PrP-WT set to $1.00 \pm 0.04 ; n=3 ; \pm$ SEM). Interestingly, as indicated by asterisks in Fig. $2 \mathrm{a}$ and d, for the unglycosylated PrP-G3 mutant we consistently detected a significant difference in the ratio of $\operatorname{PrP}$ and $\mathrm{C} 1$ between membrane-associated (fl-PrP: 61\%; C1: 39\%; $\pm 4.5 \%$ SEM; $\mathrm{n}=3$ ) and shed forms (sPrP: $21 \%$; shed $\mathrm{C} 1: 79 \%$; $\pm 6.2 \%$ ). This increase in the proportion of C1 (from 39\% in lysates to $79 \%$ among the shed PrP forms) in the absence of $\mathrm{N}$-glycans may relate to the longer half-life of $\mathrm{C} 1$ at the plasma membrane and a fast re-internalisation of unglycosylated fl-PrP [84-86] which seems to be disfavored as a substrate (Fig. 2i). In contrast, for normally glycosylated PrP-WT, there appeared to be a preference for the shedding of (diglycosylated) fl-PrP over the (diglycosylated) $\mathrm{C} 1$ fragment when comparing fl-PrP and $\mathrm{C} 1$ ratios in PNGase F digested lysates (Fig. 2b) and media supernatants (Fig. 2g). This observation prompted us to investigate a potential influence of the N-terminal half of $\operatorname{PrP}^{\mathrm{C}}$ on the membrane-proximate shedding. We therefore transfected PrP-KO N2a cells with PrP-WT or with an N-terminally truncated construct (PrP-C1) corresponding to the physiological $\mathrm{C} 1$ fragment (Additional file 5). Despite indicating that a preference for the shedding of diglycosylated forms also exists for the $\mathrm{C} 1$ fragment, shedding of the latter was significantly reduced compared to fl-PrP in cells transfected with PrP-WT. Although further analysis are clearly required and differences might partially result from transient overexpression and altered surface expression of the constructs, these findings point to a role of the PrP Nterminal domain in the C-terminal shedding event. Thus, the glycosylation state as well as proteolytic truncation seem to affect $\operatorname{PrP}^{\mathrm{C}}$ shedding.

\section{Shedding is also affected by pharmacological modulation of PrP ${ }^{C}$ glycosylation}

To support our findings obtained with PrP glycomutants (Fig. 2), we pharmacologically manipulated glycosylation in wild-type N2a cells. While the antibiotic tunicamycin (TM) inhibits N-glycosylation, the alkaloid swainsonine (SWA) is a known inhibitor of the further maturation of $\mathrm{N}$-linked glycan structures resulting in non-mature high-mannose glycans. Treatment of cells with TM completely prevented $\mathrm{N}$-glycosylation of $\mathrm{PrP}^{\mathrm{C}}$, whereas treatment with SWA resulted in a shift in the molecular weight of diglycosylated $\operatorname{PrP}^{\mathrm{C}}$ indicating immature glycosylation (Fig. 3a). Digestion of lysates with Endo $\mathrm{H}$ revealed that SWA (partially) impaired complex glycosylation as shown by an altered glycopattern compared to controls (Fig. 3b). Further confirmation for the TM- and SWA-treatments and the enzymatic deglycosylation reactions is presented in a side-by-side comparison (Additional file 6). However, it should be noted that we did not reach a complete deglycosylation in the case of Endo H-digestion of lysates of SWA-treated cells. Presence of residual complex glycosylated $\operatorname{PrP}^{\mathrm{C}}$ suggests that the incubation with SWA $(8 \mathrm{~h})$ was too short or that Endo $\mathrm{H}$ digestion was incomplete. Independent of 


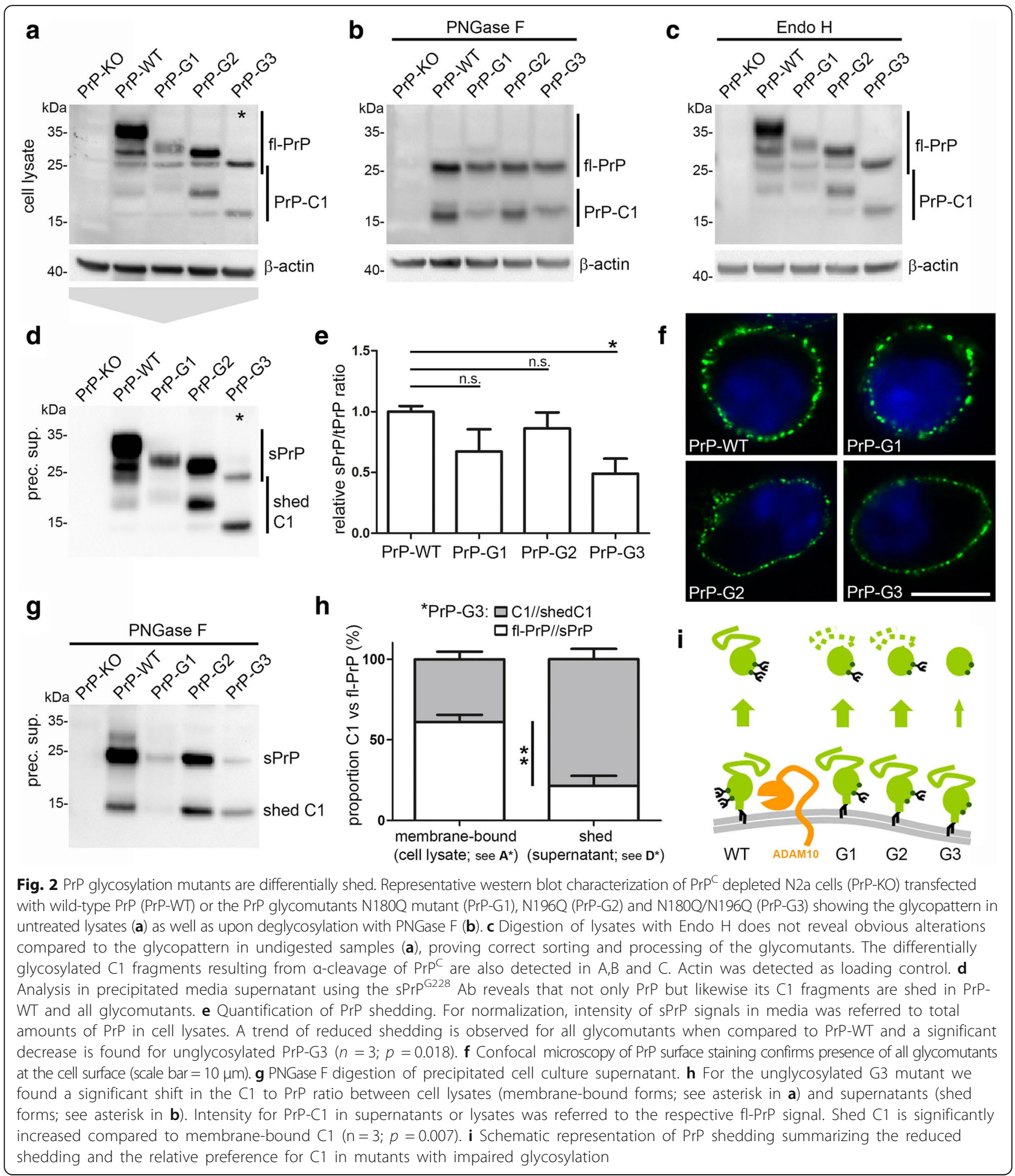

the type of treatment, $\operatorname{PrP}^{C}$ was expressed at the cellular surface (Fig. 3c). Intriguingly, $\operatorname{PrP}^{\mathrm{C}}$ shedding was almost completely abolished in cells treated with TM (mean: $0.07 \pm 0.03 ; n=3$; SEM) and significantly reduced upon treatment with SWA $(0.41 \pm 0.10)$ compared to untreated controls (set to $1.00 \pm 0.12$ )
(Fig. 3d, e). Even though only little non-mature diglycosylated $\operatorname{PrP}^{\mathrm{C}}$ was present in SWA-treated cells (Fig. 3b), this fraction seems to be the only relevant substrate for shedding. Again, these data support our previous findings (Figs. 1 and 2) showing that diglycosylated $\operatorname{PrP}$ is the preferential substrate for 

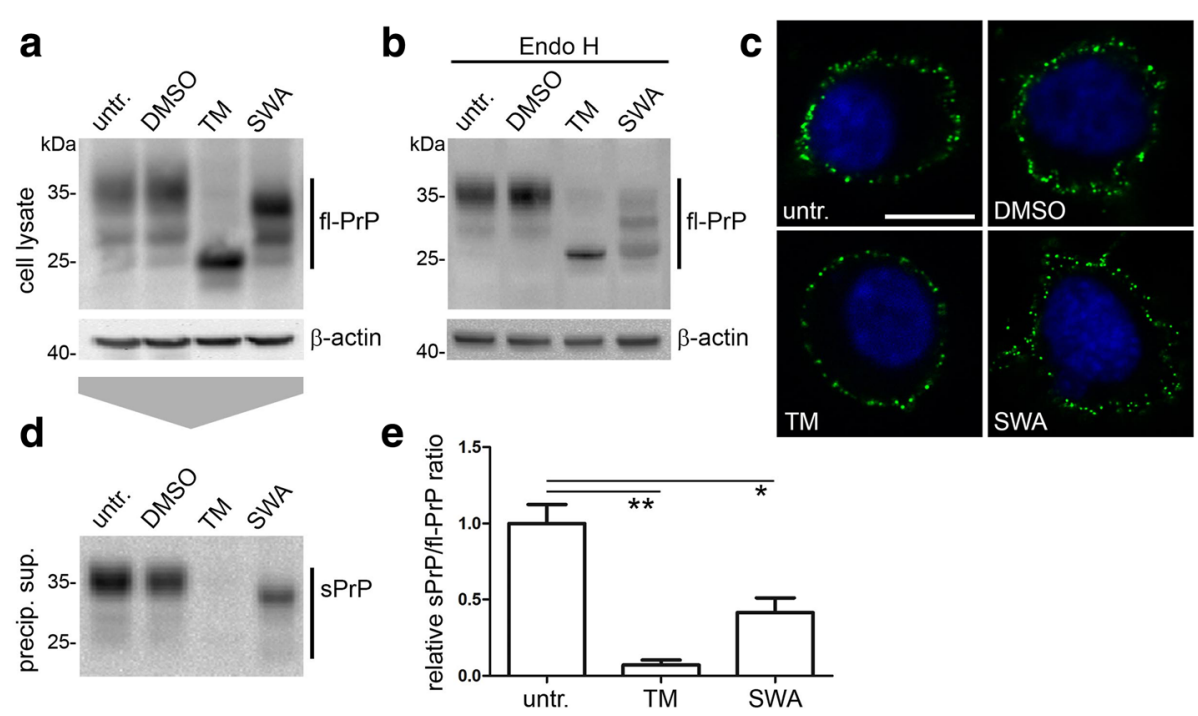

Fig. 3 Pharmacological manipulation of N-glycosylation alters PrP shedding. a Representative western blot analysis of wild-type N2a cells either left untreated or treated with DMSO (as a solvent control), $2.5 \mu \mathrm{g} / \mathrm{ml}$ tunicamycin (TM) or $5 \mu \mathrm{g} / \mathrm{ml}$ swainsonine (SWA). For TM only unglycosylated $\mathrm{PrP}$ is detected. The SWA-treated sample reveals a slight downwards shift for diglycosylated PrP compared to DMSO- and untreated samples. $\mathbf{b}$ Endo $\mathrm{H}$ digestion further demonstrates an altered glycopattern for SWA-treated cells indicating that correct maturation to complex $\mathrm{N}$-glycans was (at least partially) impaired. Actin served as loading control. c Staining on non-permeabilized cells demonstrating that, in all conditions, PrPC is sufficiently expressed at the plasma membrane. $\mathbf{d}$ Representative western blot showing shed PrP in corresponding (precipitated) media supernatants. e Quantification of shedding efficiency (measured as the ratio of shed PrP in supernatants to fl-PrP in respective lysates) showing almost abolished shedding in TM-treated $(n=3 ; p=0.002)$ and impaired shedding in SWA-treated cells $(n=3 ; p=0.020)$

ADAM10 at the cell surface and that altered glycosylation influences PrP shedding efficiency.

\section{Membrane anchorage and topology of $\operatorname{PrP}^{\complement}$ determine its shedding efficiency}

An additional modification that influences membrane topology, biological functions and pathophysiological roles of the prion protein is the type of membrane attachment. With $\operatorname{PrP}^{C}$ being one of only few GPIanchored substrates of ADAM10 [47, 87], we wondered how altered attachment and topology at the membrane would affect its shedding. To this end, we used mutants of $\operatorname{PrP}^{\mathrm{C}}$ either comprising a transmembrane domain instead of the GPI-anchor (PrP-TM) or carrying the GPI-anchor signal sequence (and -as a likely consequence- the GPI-anchor [61] (Puig et al. submitted)) of Thy-1, a protein described to reside in the dense cores of detergent-resistant membranes (herein referred to as lipid rafts) [88]. Whereas interaction between ADAM10 and $\operatorname{PrP}^{\mathrm{C}}$ is thought to occur at the interface between lipid rafts and non-raft regions (Fig. 4a), previous studies have shown that PrP-TM is relocated outside of rafts and turned signaling-incompetent $[38,63,89]$ while $\operatorname{PrP}^{\text {GPIThy-1 }}$ remains in rafts yet therein shows a different localization than PrP-WT [61] (Puig et al. submitted).
Immunofluorescent stainings of non-permeabilized cells showed surface expression (Fig. 4b) while western blot analysis revealed comparable expression of all constructs transfected into PrP-KO N2a cells (Fig. 4c). Deglycosylation of samples showed that all $\operatorname{PrP}$ mutants are subject to $\alpha$-cleavage and confirmed an increase in molecular weight for PrP-TM due to its transmembrane domain (Fig. 4d). No alterations in the banding pattern were observed upon treatment with Endo $\mathrm{H}$ indicating correct glycosylation and -again- surface transport of all mutants (Fig. 4e). Lack of signal in the media for PrP-TM upon incubation of cells with PI-PLC proved the absence of a GPI-anchor and its attachment via a transmembrane domain (Fig. 4f).

Of note, despite a conserved shedding site in all constructs, shedding was completely abolished for PrP-TM (mean: $0 \pm 0.02 ; n=3$; SEM) and significantly reduced for $\operatorname{PrP}^{\text {GPIThy-1 }}(0.33 \pm 0.06)$ compared to PrP-WT (set to $1.00 \pm 0.05)$ (Fig. 4g,h). In conclusion, altered membrane attachment and, hence, changed membrane localization severely impact on $\operatorname{PrP}^{C}$ shedding.

\section{Shedding is part of a compensatory cellular network regulating $\operatorname{PrP}^{C}$ homeostasis}

As already shown in Fig. 1f, we consistently observed an increased cellular release of PrP via alternative routes whenever the proteolytic shedding was 


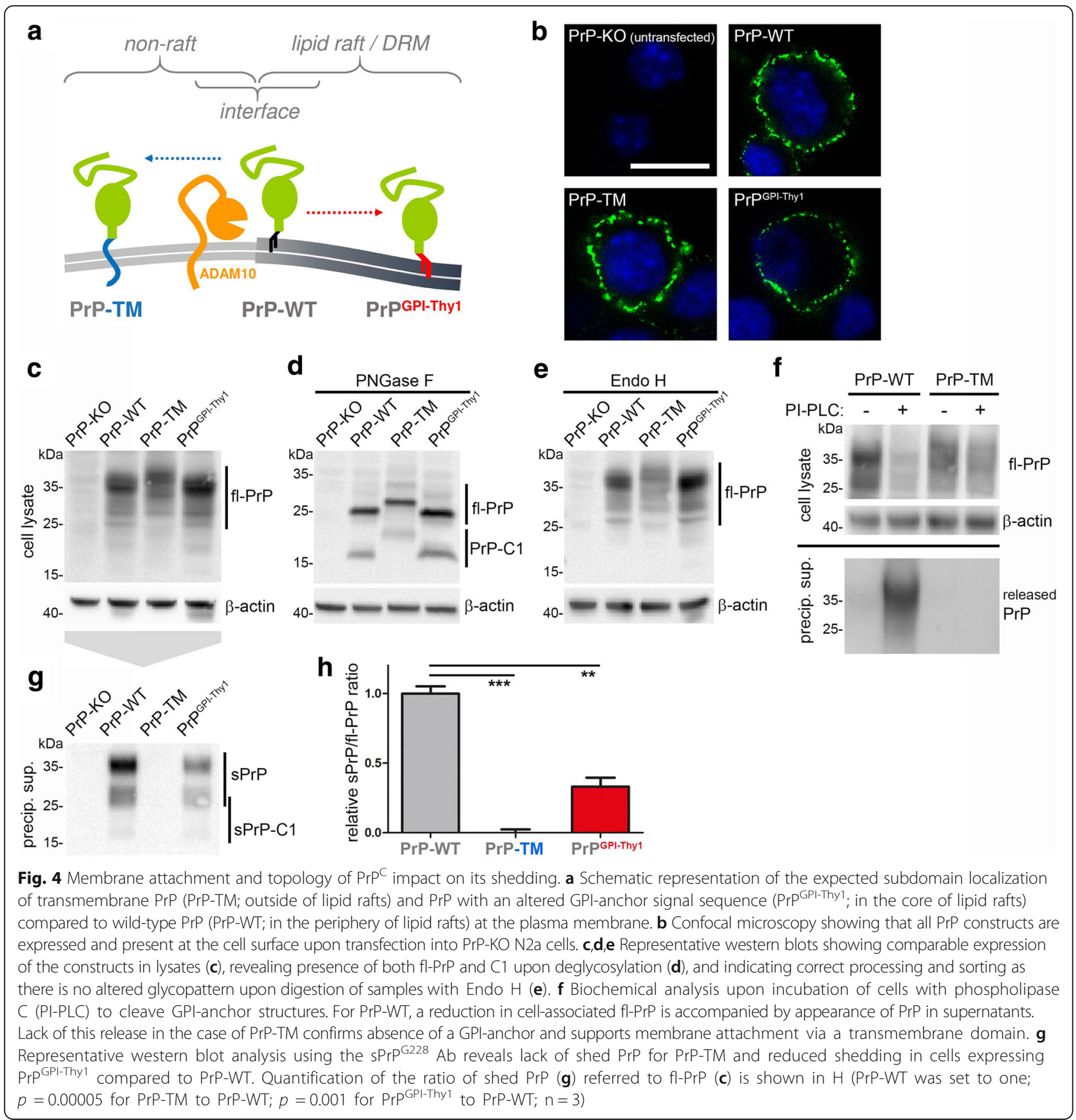

impaired (e.g. by inhibition of ADAM10 with GI; Fig. 5a). Since $\operatorname{PrP}^{C}$ is released via microvesicles (e.g. exosomes [72, 90, 91]), we wondered whether this mechanism could compensate for abolished shedding. Inhibition of ADAM10 with GI resulted in a significant rise of exosome release (mean: $1.48 \pm 0.09$; compared to controls set to $1.00 \pm 0.09 ; n=4$; SEM; Fig. $5 \mathrm{~b}$ ) without affecting the typical size of these vesicles (mean: $128 \pm$ $12 \mathrm{~nm}$; compared to controls $115 \pm 2 \mathrm{~nm}$; $\mathrm{n}=4$; SEM; Fig. $5 \mathrm{c}$; details for characterization of exosomes are shown in
Additional file 7). When amounts of exosomes were normalized, we found more than a twofold increase in their average $\operatorname{PrP}^{\mathrm{C}}$ load upon GI treatment $(2.12 \pm 0.08$; compared to controls set to $1.00 \pm 0.08 ; n=3$; SEM; Fig. $5 \mathrm{~d}, \mathrm{e})$. $\operatorname{PrP}^{\mathrm{C}}$ levels in the corresponding cells were only moderately, yet significantly increased ( $1.40 \pm 0.07$; compared to controls set to $1.00 \pm 0.07 ; \mathrm{n}=3$; SEM; Fig. $5 \mathrm{~d}, \mathrm{f})$. Thus, as a consequence of impaired shedding, more $\operatorname{PrP}^{\mathrm{C}}$ is packed into exosomes and more exosomes are released by $\mathrm{N} 2 \mathrm{a}$ cells. Interestingly, such an alternative release of $\operatorname{PrP}^{C}$ 


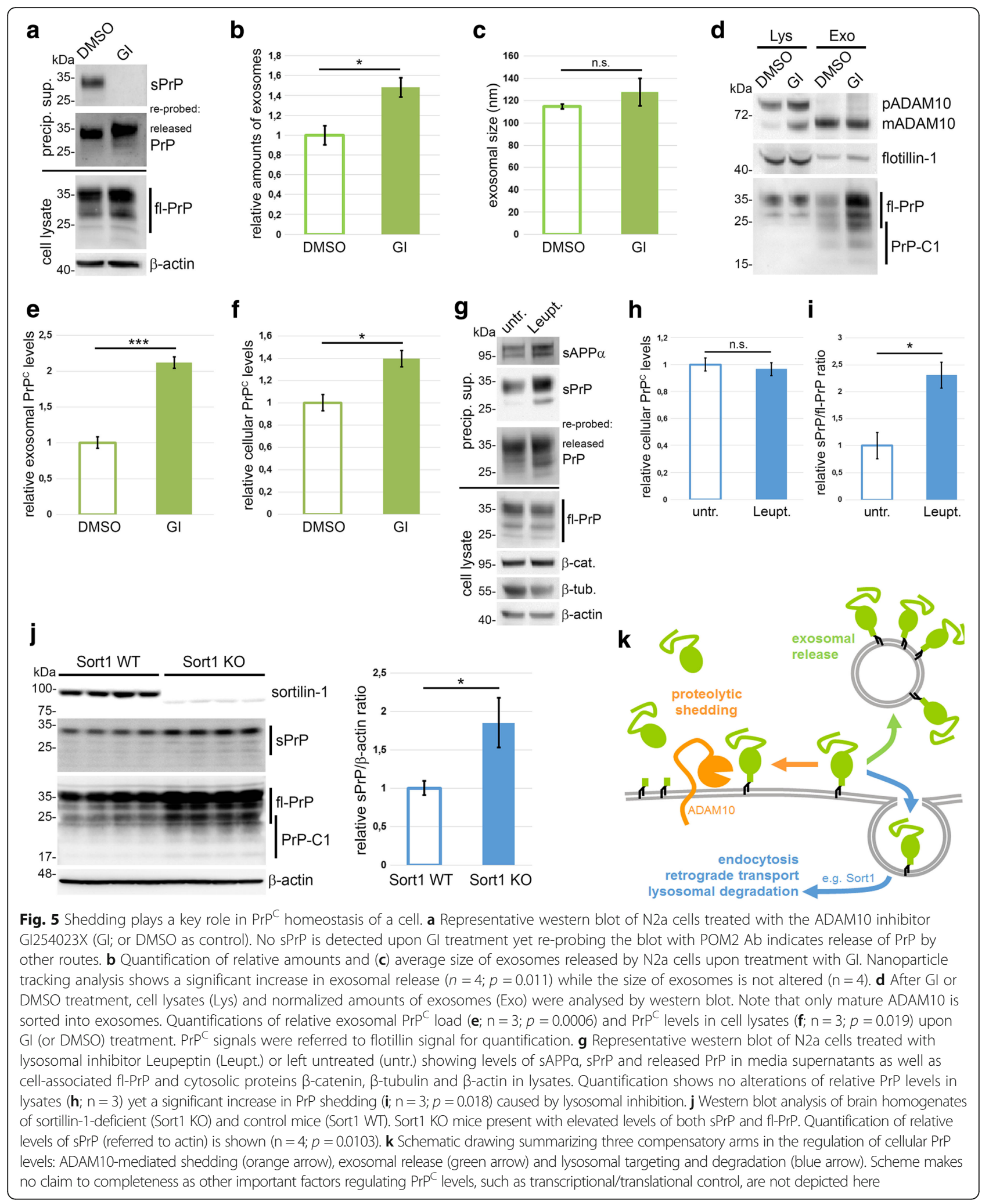

was not observed in murine fibroblasts (MEF) lacking ADAM10 (Additional file 8) [71] which instead accumulated $\mathrm{PrP}^{\mathrm{C}}$ to 3-fold the amount of wild-type MEFs (ADAM10 KO:
$3.07 \pm 0.12$; WT set to $1.00 \pm 0.12 ; n=8$; SEM). This may indicate that not all cell types possess the compensatory machinery ensuring $\operatorname{PrP}^{C}$ release and membrane homeostasis. 
Finally, we investigated how degradation, as a third aspect involved in cellular $\operatorname{PrP}^{\mathrm{C}}$ homeostasis, influences $\mathrm{PrP}^{\mathrm{C}}$ shedding. We blocked lysosomal degradation by treatment of $\mathrm{N} 2 \mathrm{a}$ cells with leupeptin. As expected, cytosolic proteins (e.g. $\beta$-actin, $\beta$-tubulin, $\beta$-catenin) known to be degraded by the proteasome rather than in lysosomes were not accumulated (Fig. 5g). Instead, increased secretion of $\mathrm{sAPP} \alpha$, the proteolytic fragment of APP, indicated successful lysosomal inhibition (Fig. 5g). Of note, cell-associated $\mathrm{PrP}^{\mathrm{C}}$ levels remained rather stable despite this treatment (Leupt.: $0.97 \pm 0.05$; untr. Cells set to $1.00 \pm 0.05 ; \mathrm{n}=3$; SEM; Fig. $5 \mathrm{~g}, \mathrm{~h})$ yet shedding of $\mathrm{PrP}^{\mathrm{C}}$ was significantly increased (Leupt.: $2.31 \pm 0.24$; untr. Cells set to $1.00 \pm 0.24 ; \mathrm{n}=3$; SEM; Fig. $5 \mathrm{~g}, \mathrm{i})$. No obvious differences in alternatively released PrP (Fig. 5g) suggests that, in this condition, shedding is the main contributor avoiding increased cellular $\operatorname{PrP}^{\mathrm{C}}$ levels.

Impaired lysosomal degradation and increased $\operatorname{PrP}^{C}$ levels have recently been shown in mice lacking the sorting receptor sortilin-1 [69]. As a consequence of hindered transport to lysosomes, these mice had shown increased $\operatorname{PrP}^{\mathrm{Sc}}$ conversion and shortened survival when infected with prions. Given the increase in shedding upon lysosomal inhibition with leupeptin in cells shown before, we asked whether shedding of $\operatorname{PrP}^{\mathrm{C}}$ is likewise affected by the impaired degradation due to lack of sortilin-dependent transport in vivo. In fact, we found an approximately 2-fold increase for sPrP in sortilin1deficient mice compared to controls (Sort1 KO: $1.85 \pm 0$. 32; Sort1 WT set to $1.00 \pm 0.09 ; n=4$; SD; Fig. 5j). Rather than from up-regulation of sheddase activity, this increase seems to result from elevated cellular $\operatorname{PrP}^{\mathrm{C}}$ levels caused by impaired degradation (Additional file 9). Nevertheless, this demonstrates the capability of ADAM10 to release increased amounts of substrate.

In summary, these data suggest ADAM10-mediated shedding as a relevant factor regulating $\operatorname{PrP}^{\mathrm{C}}$ levels. Shedding, exosomal release and degradation of $\operatorname{PrP}^{C}$ may be interconnected mechanisms that act in a compensatory manner ensuring $\operatorname{PrP}^{\mathrm{C}}$ homeostasis and allowing -if at all- only subtle changes thereof.

\section{Discussion}

Evolutionary conserved proteolytic processing of the prion protein has been described a quarter of a century ago [92-94] (reviewed in [28]). However, we are just beginning to appreciate the physiological and pathological relevance of such cleavage events, which is partially due to technical difficulties in reliable detection of the respective fragments. We here present a novel antibody that detects shed PrP with high specificity and sensitivity in different applications. Despite the existence of several valuable antibodies against various epitopes in $\operatorname{PrP}^{C}$ (e.g. the POM antibodies used in this study [73]), until now it has only been possible to detect shed PrP upon rather labor-intensive and error-prone immunoprecipitation from or strong concentration of cell culture supernatants $[47,48]$. And even that way, contribution of $\operatorname{PrP}^{C}$ released from cells by other routes (e.g. via exosomes) [91] to respective signals has to be considered. In tissue samples it has so far been impossible to specifically detect shed PrP due to the excess amounts of cell- or

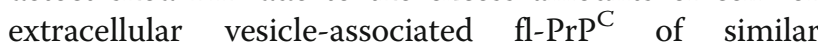
molecular weight masking any signal coming from the fraction of proteolytically shed PrP. This resulted in a lack of in vivo insight. These problems have been overcome and novel findings have been made with the new antibody.

Despite confirming antibody specificity, the absence of shed PrP in forebrain homogenates from mice with a depletion of ADAM10 in forebrain neurons to our surprise indicates that, at least under physiological conditions, no other cell types in the brain contribute to shedding in a detectable manner. It also questions a shedding of (neuronal) $\operatorname{PrP}^{\mathrm{C}}$ in trans (e.g. by adjacent glia cells not depleted of the protease), a mechanism that has been shown for the ADAM10 substrate ephrin in HEK cells [95]. Our findings of abolished shedding in the absence of ADAM10 or upon pharmacological inhibition of ADAM10 also indicate that no other protease compensates for these manipulations in vitro or in vivo. Further support comes from mice coexpressing dominant negative ADAM10 with endogenous ADAM10, where we found a comparably strong ( 50\%) reduction in $\operatorname{PrP}$ shedding. Instead, previous western blot analyses of SAPP $\alpha$ in ADAM10 d.n. mice only showed a reduction of $\sim 25 \%[96,97]$ hinting at the known contribution of ADAM17/TACE in the cleavage of APP [98]. It should be considered that cleavage by another protease at a slightly different cleavage site would prevent detection with our antibody. However, our previous results obtained by pull-down of shed PrP from media of primary ADAM10 knockout neurons with classical PrP antibodies [48], together with a recent biophysical study [31], and the lack of any other reported candidate protease linked to the membraneproximate shedding of $\mathrm{PrP}^{\mathrm{C}}$, support the view of ADAM10 as the only relevant sheddase of $\mathrm{PrP}^{\mathrm{C}}$. This is in clear contrast to the cleavage of other typical ADAM10 substrates such as APP, which -as mentioned above- to varying degrees and dependent on the experimental paradigm, can also be processed by other proteases [71, 99-101].

Our analysis suggests that diglycosylated $\mathrm{PrP}^{\mathrm{C}}$ is the preferred glycoform to be shed by ADAM10, whereas mono- and especially unglycosylated forms seem to be relatively disfavored. Our data also indicates that this 
finding not simply results from differences in the availability of individual glycoforms as substrates at the plasma membrane under normal conditions (our transfected glycomutants as well as $\operatorname{PrP}^{\mathrm{C}}$ in cells treated with TM or SWA were by all means localized at the surface). An alternative explanation could be that shed diglycosylated $\operatorname{PrP}$ is more protected than the other shed forms from potential cellular uptake and degradation and, thus, more abundant. In any case, among all soluble $\operatorname{PrP}^{C}$ fragments released from the cell by the proteolytic cleavages described to date, shed PrP is the only one that is glycosylated. As discussed earlier [28] this may well impact its binding affinities to both, toxic extracellular oligomers as well as physiological binding partners (e.g. surface signaling receptors), and thus define its specific biological functions. Moreover, by the predominantly diglycosylated state, physiologically shed PrP clearly differs from anchorless, mainly unglycosylated PrP of transgenic mice used in several seminal prion inoculation studies in the past $[54,102-104]$. This difference has to be considered and, in the context of prion diseases, might explain why transgenic anchorless $\operatorname{PrP}$ efficiently converts to $\operatorname{PrP}^{\mathrm{Sc}}$ and can even spontaneously form prions [54, 103], whereas shed PrP rather seems to block $\mathrm{PrP}^{\mathrm{Sc}}$ formation in mice [50]. Fittingly, the N-glycans are known to influence transmissibility and conversion to $\operatorname{PrP}^{\mathrm{Sc}}[62,80-83]$.

Altered shedding efficiency for different glycoforms, however, might in part also be caused by a different sorting given that the glycans have a significant impact on the polarized trafficking of $\operatorname{PrP}^{C}$ in MDCK cells [61]. Despite a role for the $\mathrm{N}$-glycans, we also demonstrated that changes in the type of membrane anchorage and, as a likely consequence, altered membrane topology affects shedding. Shifting $\operatorname{PrP}^{\mathrm{C}}$ outside of rafts by addition of a transmembrane domain [63, 89] completely abolished the shedding while the assumed re-localization of $\operatorname{PrP}^{\mathrm{C}}$ within lipid rafts via exchange of the GPI-anchor signal sequence $[61,88]$ reduced shedding to $\sim 30 \%$ in $\mathrm{N} 2 \mathrm{a}$ cells. The latter is in good agreement with unpublished data obtained in transgenic mice expressing the same PrP $\mathrm{P}^{\text {GPIThy-1 }}$ construct (Puig et al., submitted). Instead of changing the anchorage of the substrate as done here, others have changed membrane attachment of the protease [105]. Lipid raft targeting of ADAM10 by addition of a GPI-anchor in that study severely affected APP processing. Unfortunately, processing of $\operatorname{PrP}^{\mathrm{C}}$ was not investigated there.

Since ADAM10 is mainly located outside of lipid rafts $[105,106]$, whereas $\operatorname{PrP}^{C}$ is a resident of these microdomains, transient interaction between protease and substrate (presumably regulated by accessory proteins such as tetraspanins [107-109]) and cleavage is thought to occur at the periphery of rafts. This molecular get-together might further be supported by the capacity of $\operatorname{PrP}^{C}$ to leave and re-enter lipid rafts in a constitutive manner [85, 110, 111]. Our findings also suggest an impact of the flexible $\mathrm{N}$-terminal part of $\operatorname{PrP}^{\mathrm{C}}$ on the shedding efficiency. Whether this unanticipated influence is due to sterical aspects or rather reflects the role of regulatory binding partners known to especially interact with the N-terminal half of $\operatorname{PrP}^{C}[5,27,112]$, deserves further investigations.

Our data indicate that shedding is a relevant mechanism embedded in a compensatory machinery ensuring homeostasis of $\operatorname{PrP}^{C}$. In neurons and neuronal cells, this system (involving proteolytic and exosomal release as well as trafficking to lysosomes) seems to ensure that cell-associated $\operatorname{PrP}^{\mathrm{C}}$ levels are kept stable or -at mostincrease twofold upon perturbation (as indicated in some experiments of this study and observed in neurons or mice lacking the sheddase ADAM10 $[48,50]$ or the transport factor sortilin-1 [69]). Interestingly, a recent study showed that exosomal release is controlled by $\operatorname{PrP}^{\mathrm{C}}$ membrane levels [113]. Though clearly requiring further investigation, it might be speculated that other cell types, such as fibroblasts studied here, do not possess the system to compensate for such perturbation in one of the mechanisms discussed above, and consequently accumulate $\operatorname{PrP}^{\mathrm{C}}$ to higher levels.

Manipulation of $\operatorname{PrP}^{C}$ shedding is feasible and might be of therapeutic interest. Despite the challenge by possible side effects due to the broad spectrum of ADAM10 substrates, one obvious question then is into which direction to modify $\operatorname{PrP}^{C}$ shedding $[87,114]$.

With regard to neurodegenerative proteinopathies, such as Alzheimer's or prion diseases, stimulation of this cleavage will likely be beneficial. First, it reduces $\mathrm{PrP}^{\mathrm{C}}$ levels at the cell surface and may thereby lower neurotoxicity. Moreover, several studies showed that soluble PrP targets toxic oligomers and fibrils in the extracellular space $[55-58,115]$. In prion diseases, shedding efficiency inversely correlates with $\operatorname{PrP}^{\mathrm{Sc}}$ formation [50, 52]. Notably, resveratrol, the drug that was used here to stimulate shedding, reduced $\operatorname{PrP}^{\mathrm{Sc}}$ formation and prion infectivity in a recent study [116]. Whether this anti-prion efficacy is indeed related to shedding, remains to be investigated. Besides proteinopathies, positive effects of stimulated shedding can also be expected given the potential role of this fragment in neurite outgrowth $[13,14]$ and neuroprotection $[15,49]$. In that way, the role of shed $\operatorname{PrP}$ is reminiscent of sAPP $\alpha$, the APP-derived fragment also generated by ADAM10 [117].

Other pathological conditions, in contrast, may rather require inhibition of $\operatorname{PrP}^{\mathrm{C}}$ shedding: it is intriguing that both, ADAM10 $[118,119]$ and $\operatorname{PrP}^{\mathrm{C}}$, have been linked with immune signaling and chronic inflammatory 
processes $[120,121]$ as well as with tumorigenesis and cancer progression [122-124], where expression levels of these two proteins generally correlate with poor prognosis. Though this could well be unrelated coincidence, it might also be speculated that these pathophysiological roles are partially related to the production of shed PrP. Of note, it is precisely shed PrP that was causally linked with chronic inflammatory neuropathology in HIV patients [60] and development of tumours in the central nervous system [59] in two recent studies. This further supports the relevance of shed PrP in different pathophysiological conditions and highlights the need for further studies on the ADAM10-mediated shedding of $\operatorname{PrP}^{\mathrm{C}}$.

\section{Conclusion}

Proteolytic shedding of the prion protein has most recently attracted scientific interest with regard to diverse pathological conditions affecting the brain. Using a novel antibody for the specific detection of shed PrP, we demonstrated structural and regulatory aspects influencing this cleavage and show that it can - in principle - be pharmacologically manipulated. The latter, together with the rather ubiquitous expression of $\operatorname{PrP}^{\mathrm{C}}$ in several tissues and cell lines, as well as the lack of compensation by other proteases discussed above, also turns (i) $\operatorname{PrP}^{C}$ into an ideal "control" substrate, (ii) assessment of $\operatorname{PrP}^{\mathrm{C}}$ shedding into a reliable "read out", and (iii) our antibody into a valuable tool for any future studies investigating ADAM10-mediated cleavages and their pharmacological accessibility. With direct regard to the shedding of $\mathrm{PrP}^{\mathrm{C}}$, both, therapeutic stimulation as well as inhibition, may be conceivable depending on the pathological context.

\section{Additional files}

Additional file 1: (.jpg) The 3F4-tag in $\operatorname{PrP}^{C}$ does not alter the ADAM10mediated shedding. Western blot analysis of forebrain homogenates comparing $\mathrm{PrP}^{C}$ shedding between mice expressing endogenous wildtype $\operatorname{Pr} P^{C}\left(\operatorname{PrP}{ }^{C} W T\right)$ and knock-in mice expressing 3F4-tagged PrPC instead ( $\left.\mathrm{PrP}^{3 \mathrm{~F} 4} \mathrm{KI}\right)$. Quantification was done by referring the $\mathrm{SPrP}$ signal to the respective fl-PrP signal (POM2 $\mathrm{Ab}$ ) of the re-probed blot and is shown on the right $(n=3)$. As in other parts of this study, forebrain homogenates of Prnp ${ }^{0 / 0}$, ADAM10 CKO and tga20 mice served as specificity controls. The position of air bubbles on the membrane (indicated by arrows) further supports the slight molecular weight shift between sPrP and fl-PrP described in Fig. 1b. To prove genotypes of $\operatorname{PrP}^{\mathrm{C}} \mathrm{WT}$ and $\operatorname{PrP}^{3 \mathrm{~F}}{ }^{\mathrm{K}} \mathrm{Kl}$ mice, in a parallel blot shown below, PrPC was first detected with an antibody directed against the 3F4 epitope and re-probed with POM2. (JPEG $225 \mathrm{~kb}$ )

Additional file 2: (.jpg) Species specificity of the $\operatorname{sPrP}^{\mathrm{G} 228}$ antibody. (A) Comparison of the C-terminal amino acid sequence of $\operatorname{PrP}^{C}$ in mouse (Mus musculus), rat (Rattus norvegicus) and rabbit (Oryctolagus cuniculus) (source: www.uniprot.org). " $\mathrm{NH}_{2}-\ldots-{ }^{-1}$ indicates the $\mathrm{N}$-terminal direction, "-GPl" the C-terminal GPI-anchor attachment site. Asterisks indicate position of ADAM10-mediated shedding in mice and rats with Gly228 representing the new C-terminus of shed PrP. Note the sequence difference compared with rabbit PrPC . (B) Western blot analysis of forebrain

homogenates from different murine models (tga20, Prnpo/0, wild-type (C57BL/6)) as well as from rat and rabbit. As expected for its epitope, the SPrP ${ }^{\mathrm{G} 228}$ antibody detects SPrP in mouse (tga20 and wild-type) and rat, whereas the brain sample of rabbit only presents an immunoglobulin light chain (rb lg-LC) signal at $25 \mathrm{kDa}$ resulting from the anti-rabbit secondary antibody used for detection. Re-probing the blot with POM2 antibody reveals expression levels of PrPC. (JPEG $388 \mathrm{~kb}$ )

Additional file 3: (.jpg) Use of the sPrP ${ }^{\mathrm{G} 228}$ antibody for immunohistochemical stainings. Sagittal brain sections of a Prnp ${ }^{0 / 0}$, a wild-type (C57BL/6) and a tga20 mouse stained with hematoxilin/eosin (H\&E), an antibody against total PrPC (SAF84), or the SPrP Ab showing the hippocampus $(\mathrm{Hc})$ and parts of cortical areas $(\mathrm{CX})$ in overviews. Magnifications are shown for the corpus callosum and CA1 region (upper insets) as well as for the dentate gyros (DG) and CA3 region (lower insets) of the hippocampus. With the $\operatorname{SPrP}^{\mathrm{G} 228} \mathrm{Ab}$, a diffuse brownish staining of the brain parenchyma is seen for wild-type and tga20 whereas Prnpo/ ${ }^{0}$ brain only shows blue counterstaining. Comparison with the SAF84 staining reveals that levels of shed PrP correlate with overall PrPC expression. Scale bars represent $100 \mu \mathrm{m}$. (JPEG $1948 \mathrm{~kb}$ )

Additional file 4: (.jpg) Differences in the glycopattern between total and cell surface PrPC in N2a cells. (A) Western blot analysis and (B) densitometric quantification of glycoform proportions of total (cell lysates) versus cell surface fl-PrP (biotinylated samples) using POM2 antibody for detection. Absence of actin and almost exclusive expression of mature ADAM10 (with almost no premature ADAM10) in the biotinylated samples confirm technical soundness of the assay (the upwards shift of ADAM10 in gel likely results from the assay protocol). Quantification reveals that the fraction of diglycosylated PrP at the cell surface is increased compared to total PrP in cell lysates (diglycosylated: $68.0 \pm 0.7 \%$ (surface PrP) vs. $55.1 \pm 2.4 \%$ (total PrP); monoglycosylated: $23.5 \pm 0.8 \%$ (surface PrP) vs. $29.3 \pm 0.6 \%$ (total PrP); unglycosylated: $8.5 \pm 0.2 \%$ (surface PrP) vs. $15.5 \pm 1.9 \%$ (total PrP); $n=3 ; \pm S D)$. (JPEG $610 \mathrm{~kb}$ )

Additional file 5: (.jpg) Preference for the shedding of fl-PrP over truncated $\mathrm{C} 1$ fragment indicates a role of the $\mathrm{N}$-terminal part of $\mathrm{PrP}^{\mathrm{C}}$. Western blot analysis of PrP-KO N2a cells transfected with PrP-WT or N-terminally truncated PrP-C1 (corresponding to physiological C1 fragment). Analysis of cell lysates (on the left) reveals N-glycosylation and comparable expression levels for both constructs. Actin served as loading control. Enzymatic deglycosylation (PNGase F) was performed and samples run on a parallel blot to confirm identity of constructs. POM1 antibody was used for detection of $\mathrm{PrP}^{C}$ in lysates. Corresponding cell culture supernatants were precipitated and run on a parallel blot (on the right) and shed PrP forms were detected with SPrPG228 antibody. Released sAPPa was detected as loading control for supernatants. Signal intensities of shed PrP forms ( $\mathrm{SPrP}^{\mathrm{G} 228} \mathrm{Ab}$ ) were referred to total PrP signal intensities in lysates (POM1) and quantification reveals a significantly reduced shedding for PrP-C1 (relative ratio shed/total PrP: $0.12 \pm 0.03$ ) compared to (full-length) PrP-WT (set to $1.00 \pm 0.11$; $p=0.0017 ; n=3 ; \pm$ SEM). (JPEG $799 \mathrm{~kb}$ )

Additional file 6: (.jpg) Side-by-side comparison of SWA and TM treatments and enzymatic deglycosylation reactions. Western blot of untreated (untr.), SWA- or TM-treated N2a cells showing lysates without (-) or with (+) enzymatic treatment for differential deglycosylation (Endo H or PNGase F). As also shown in Fig. 3a and b, TM-treatment causes a complete inhibition of PrP glycosylation, whereas SWA-treatment results in a shift in the banding pattern (compared to untreated cells) and (at least partial) Endo $\mathrm{H}$ sensitivity due to inhibition of complex glycosylation. Changes in the glycopattern and running behaviour support the functioning of our enzymatic deglycosylation protocols also performed for the experiments shown in Figs. 2, 3 and 4. Actin is shown as a loading control. (JPEG $221 \mathrm{~kb}$ )

Additional file 7: (.jpg) Exosome characterization using the NanoSight system. Representative experiment showing the raw data of 10 serial measures (upper curves) and the averaged data (lower curves) derived from media supernatants of DMSO- or GI254023X (GI)-treated N2a cells. $X$-axis: size (nm); Y-axis: concentration (E6 particles $/ \mathrm{ml})$. Blue numbers at the tips of curves represent mean sizes. (JPEG $348 \mathrm{~kb}$ ) 
Additional file 8: (.jpg) Embryonic fibroblasts (MEF) of ADAM10 knockout mice accumulate PrPC . Representative western blot of media supernatants and lysates of wild-type (WT) and ADAM10 KO MEF. Lack of shedding and no increased compensatory release of PrP is observed in ADAM10 KO cells. ADAM10 is shown in lysates as a proof of genotypes. Increased levels of $\operatorname{PrP}^{C}$ are found in lysates and quantified by referring to $\beta$-actin ( $n=8 ; p=0.00005)$. (JPEG $131 \mathrm{~kb}$ )

Additional file 9: (.jpg) Quantification of fl-PrP levels and ratio of sPrP/flPrP in Sort1 knockout mice. These quantifications refer to main Fig. 5j. (A) Increased amounts of fl-PrP are found in brains of Sort1 KO mice (2.11 \pm $0.23 ; p=0.0004 ; n=4)$ compared to controls (WT set to $1.00 \pm 0.21 ; S D$ ). Actin served as loading control and for reference in densitometric quantification. (B) No significant differences are detected in the ratio of sPrP to fl-PrP between Sort1 KO mouse brains $(0.85 \pm 0.07, p=$ $0.128 ; n=4)$ and controls (WT set to $1.00 \pm 0.14$ ). (JPEG 229 kb)

\section{Abbreviations}

Ab: antibody; ADAM: a disintegrin and metalloproteinase; AIDS: acquired immunodeficiency syndrome; APP: Amyloid precursor protein; AB: Amyloidbeta peptide; BSA: bovine serum albumin; BSE: bovine spongiform encephalopathy; cKO: conditional knockout; d.n.: dominant negative; DMSO: dimethyl sulfoxide; FBS: fetal bovine serum; fl-PrP: full length prion protein; Gl: GI254023X (ADAM10 inhibitor); GPI: glycosylphosphatidylinositol: HIV: human immunodeficiency virus; Kl: knock-in; KO: knockout; MDCK: Madin-Darby Canine Kidney (cells); MEF: murine embryonal fibroblasts; NaDOC: sodium deoxycholate; PBS: phosphate buffered saline; PI: protease inhibitor; PI-PLC: phosphatidylinositol-specific phospholipase C; Prnp ${ }^{0 / 0}$ : PrP ${ }^{C}$ knockout; PrPC: cellular prion protein; PrP ${ }^{S c}$ : pathological (Scrapie) isoform of the prion protein; PrP-TM: transmembrane PrP; Sort1: sortilin-1; sPrP: shed PrP; sPrP ${ }^{\text {G228. }}$ antibody against shed PrP; SWA: swainsonine; TACE: tumor necrosis factor a converting enzyme (ADAM17); TALEN: Transcription Activator-like Effector Nuclease; TBS: Trisbuffered saline; TCA: trichloroacetic acid; tga20: prion protein overexpressing mouse line; TM: Tunicamycin; WT: wild-type

\section{Acknowledgements}

We thank Dr. Dirk Kamin (Department of NanoBiophotonics, Max Planck Institute for Biophysical Chemistry, Göttingen, Germany), Kristin Hartmann (Mouse Pathology Core Unit, UKE, Hamburg, Germany) and the UKE Microscopy Imaging Facility (umif) for technical support. We apologize to all colleagues whose important contributions to this field could not be cited due to space limitations.

\section{Funding}

We are thankful for support by the Deutsche Forschungsgemeinschaft (DFG) Sonderforschungsbereich 877 (projects A12 (to HCA, PS and MG) and A3 (to PS)), the Creutzfeldt-Jakob Disease Foundation, Inc. (to HCA) and the WernerOtto-Stiftung (to LL, BP and HCA).

\section{Availability of data and materials}

The datasets used and/or analyzed during the current study are available from the corresponding author on reasonable request. The authors will be happy to provide the SPrP ${ }^{G 228}$ antibody characterized herein as research tool on reasonable request.

\section{Authors' contributions}

Conceptualization and design of the study: LL, MG and HCA; Methodology and investigation: $\mathrm{LL}, \mathrm{BM}, \mathrm{SW}, \mathrm{BP}, \mathrm{AH}, \mathrm{KU}, \mathrm{HCA}$; Providing important research resources, materials and scientific input: WSJ, SS, KE, JT, PS, MG and HCA; Writing the original manuscript draft: $L L, M G$ and HCA; Review and Editing: all authors; Supervision: MG and HCA. All authors read and approved the final manuscript.

\section{Authors' information}

Not applicable.

\section{Ethics approval}

No experiments on living animals were conducted for this study. However, housing and sacrification of animals as well as use of animal material in this study was in strict compliance with the Guide for the Care and Use of Laboratory Animals and ethics guidelines of the responsible local authorities.

\section{Consent for publication}

Not applicable.

\section{Competing interests}

The authors declare that they have no competing interests.

\section{Publisher's Note}

Springer Nature remains neutral with regard to jurisdictional claims in published maps and institutional affiliations.

\section{Author details}

${ }^{1}$ Institute of Neuropathology, University Medical Center Hamburg-Eppendorf (UKE), Hamburg, Germany. ${ }^{2}$ Institute of Biochemistry, Christian Albrechts University, Kiel, Germany. ${ }^{3}$ German Center for Neurodegenerative Diseases (DZNE), Bonn, Germany. ${ }^{4}$ Division of Molecular Neurobiology, Institute of Enzyme Research, Tokushima University, Tokushima, Japan. ${ }^{5}$ Department of Psychiatry and Psychotherapy, University Medical Center, Johannes Gutenberg University, Mainz, Germany. ${ }^{6}$ Institute of Biochemistry and Pathobiochemistry, Ruhr University, Bochum, Germany.

Received: 4 December 2017 Accepted: 21 March 2018

Published online: 06 April 2018

References

1. Seidah NG, et al. The multifaceted proprotein convertases: their unique, redundant, complementary, and opposite functions. J Biol Chem. 2013; 288(30):21473-81.

2. Aguzzi A, Baumann F, Bremer J. The prion's elusive reason for being. Annu Rev Neurosci. 2008;31:439-77.

3. Castle AR, Gill AC. Physiological functions of the cellular prion protein. Front Mol Biosci. 2017:4:19.

4. Nuvolone M, et al. Strictly co-isogenic C57BL/6J-Prnp-/- mice: a rigorous resource for prion science. J Exp Med. 2016;213(3):313-27.

5. Wulf MA, Senatore A, Aguzzi A. The biological function of the cellular prion protein: an update. BMC Biol. 2017;15(1):34.

6. Steele $A D$, et al. Prion protein ( $\mathrm{Pr} P$ C) positively regulates neural precursor proliferation during developmental and adult mammalian neurogenesis. Proc Natl Acad Sci U S A. 2006;103(9):3416-21.

7. Halliez $S$, et al. To develop with or without the prion protein. Front Cell Dev Biol. 2014;2:58.

8. Malaga-Trillo $E$, et al. Regulation of embryonic cell adhesion by the prion protein. PLoS Biol. 2009;7(3):e55.

9. Schmitt-Ulms G, et al. Binding of neural cell adhesion molecules (N-CAMs) to the cellular prion protein. J Mol Biol. 2001;314(5):1209-25.

10. Graner $\mathrm{E}_{\text {, et }}$ al. Cellular prion protein binds laminin and mediates neuritogenesis. Brain Res Mol Brain Res. 2000;76(1):85-92.

11. Chen $\mathrm{S}$, et al. Prion protein as trans-interacting partner for neurons is involved in neurite outgrowth and neuronal survival. Mol Cell Neurosci. 2003;22(2):227-33.

12. Santuccione A, et al. Prion protein recruits its neuronal receptor NCAM to lipid rafts to activate p59fyn and to enhance neurite outgrowth. J Cell Biol. 2005;169(2):341-54

13. Kanaani J, et al. Recombinant prion protein induces rapid polarization and development of synapses in embryonic rat hippocampal neurons in vitro. J Neurochem. 2005;95(5):1373-86.

14. Amin L, et al. Characterization of prion protein function by focal neurite stimulation. J Cell Sci. 2016;129(20):3878-91.

15. Bounhar $Y$, et al. Prion protein protects human neurons against BaXmediated apoptosis. J Biol Chem. 2001;276(42):39145-9.

16. Roucou X, Gains M, LeBlanc AC. Neuroprotective functions of prion protein. J Neurosci Res. 2004;75(2):153-61.

17. Guillot-Sestier MV, et al. The alpha-secretase-derived N-terminal product of cellular prion, N1, displays neuroprotective function in vitro and in vivo. J Biol Chem. 2009;284(51):35973-86.

18. Tobler l, et al. Altered circadian activity rhythms and sleep in mice devoid of prion protein. Nature. 1996;380(6575):639-42.

19. Baumann $F$, et al. Lethal recessive myelin toxicity of prion protein lacking its central domain. EMBO J. 2007;26(2):538-47. 
20. Bremer J, et al. Axonal prion protein is required for peripheral myelin maintenance. Nat Neurosci. 2010;13(3):310-8.

21. Kuffer $A$, et al. The prion protein is an agonistic ligand of the $G$ proteincoupled receptor Adgrg6. Nature. 2016;536(7617):464-8.

22. Brown DR, et al. The cellular prion protein binds copper in vivo. Nature. 1997;390(6661):684-7.

23. Watt NT, et al. Prion protein facilitates uptake of zinc into neuronal cells. Nat Commun. 2012:3:1134

24. Mouillet-Richard S, et al. Signal transduction through prion protein. Science. 2000;289(5486):1925-8.

25. Chiarini LB, et al. Cellular prion protein transduces neuroprotective signals. EMBO J. 2002;21(13):3317-26.

26. Lewis $\mathrm{V}$, Hooper NM. The role of lipid rafts in prion protein biology. Front Biosci (Landmark Ed). 2011;16:151-68.

27. Linden R. The biological function of the prion protein: a cell surface scaffold of signaling modules. Front Mol Neurosci. 2017;10:77.

28. Linsenmeier $L$, et al. Diverse functions of the prion protein - does proteolytic processing hold the key? Biochim Biophys Acta. 2017;

29. Altmeppen $\mathrm{HC}$, et al. Proteolytic processing of the prion protein in health and disease. Am J Neurodegener Dis. 2012;1(1):15-31.

30. Mays $C E$, et al. Endoproteolytic processing of the mammalian prion glycoprotein family. FEBS J. 2014;281(3):862-76.

31. McDonald AJ, et al. A new paradigm for enzymatic control of alphacleavage and beta-cleavage of the prion protein. J Biol Chem. 2014;289(2): 803-13.

32. Prusiner SB. Novel proteinaceous infectious particles cause scrapie. Science. 1982;216(4542):136-44

33. Aguzzi A, Falsig J. Prion propagation, toxicity and degradation. Nat Neurosci. 2012;15(7):936-9.

34. Collinge J. Mammalian prions and their wider relevance in neurodegenerative diseases. Nature. 2016;539(7628):217-26

35. Basler K, et al. Scrapie and cellular PrP isoforms are encoded by the same chromosomal gene. Cell. 1986;46(3):417-28.

36. Silveira JR, et al. The most infectious prion protein particles. Nature. 2005; 437(7056):257-61.

37. Wang $F$, et al. Generating a prion with bacterially expressed recombinant prion protein. Science. 2010;327(5969):1132-5

38. Resenberger UK, et al. The cellular prion protein mediates neurotoxic signalling of beta-sheet-rich conformers independent of prion replication. EMBO J. 2011;30(10):2057-70.

39. Lauren J, et al. Cellular prion protein mediates impairment of synaptic plasticity by amyloid-beta oligomers. Nature. 2009:457(7233):1128-32.

40. Um JW, et al. Metabotropic glutamate receptor 5 is a coreceptor for Alzheimer abeta oligomer bound to cellular prion protein. Neuron. 2013; 79(5):887-902.

41. Dohler $\mathrm{F}$, et al. High molecular mass assemblies of amyloid-beta oligomers bind prion protein in patients with Alzheimer's disease. Brain. 2014;137(Pt 3): 873-86.

42. Haas LT, et al. Metabotropic glutamate receptor 5 couples cellular prion protein to intracellular signalling in Alzheimer's disease. Brain. 2016;139(Pt 2): 526-46.

43. Ferreira DG, et al. alpha-synuclein interacts with PrPC to induce cognitive impairment through mGluR5 and NMDAR2B. Nat Neurosci. 2017;20(11): 1569-79.

44. Urrea $\mathrm{L}$, et al. The cellular prion protein (PrPC) as neuronal receptor for alpha-synuclein. Prion. 2017;11(4):226-33.

45. Altmeppen $\mathrm{HC}$, et al. Roles of endoproteolytic alpha-cleavage and shedding of the prion protein in neurodegeneration. FEBS J. 2013 280(18):4338-47.

46. Beland M, Roucou X. Taking advantage of physiological proteolytic processing of the prion protein for a therapeutic perspective in prion and Alzheimer diseases. Prion. 2014;8(1):106-10.

47. Taylor DR, et al. Role of ADAMs in the ectodomain shedding and conformational conversion of the prion protein. J Biol Chem. 2009;284(34): 22590-600.

48. Altmeppen $\mathrm{HC}$, et al. Lack of a-disintegrin-and-metalloproteinase ADAM10 leads to intracellular accumulation and loss of shedding of the cellular prion protein in vivo. Mol Neurodegener. 2011;6:36.

49. Race $B$, et al. Prion protein on astrocytes or in extracellular fluid impedes neurodegeneration induced by truncated prion protein. Exp Neurol. 2009; 217(2):347-52
50. Altmeppen HC, et al. The sheddase ADAM10 is a potent modulator of prion disease. elife. 2015:4

51. Glatzel M, et al. Shedding light on prion disease. Prion. 2015;9(4):244-56.

52. Endres $\mathrm{K}$, et al. Influence of ADAM10 on prion protein processing and scrapie infectiosity in vivo. Neurobiol Dis. 2009;36(2):233-41.

53. Meier $P$, et al. Soluble dimeric prion protein binds $\operatorname{Pr} P(S c)$ in vivo and antagonizes prion disease. Cell. 2003;113(1):49-60.

54. Chesebro B, et al. Anchorless prion protein results in infectious amyloid disease without clinical scrapie. Science. 2005;308(5727):1435-9.

55. Calella AM, et al. Prion protein and Abeta-related synaptic toxicity impairment. EMBO Mol Med. 2010;2(8):306-14.

56. Nieznanski K, et al. Soluble prion protein inhibits amyloid-beta (Abeta) fibrillization and toxicity. J Biol Chem. 2012;287(40):33104-8.

57. Fluharty $\mathrm{BR}$, et al. An N-terminal fragment of the prion protein binds to amyloid-beta oligomers and inhibits their neurotoxicity in vivo. J Biol Chem. 2013;288(11):7857-66.

58. Scott-McKean JJ, et al. Soluble prion protein and its N-terminal fragment prevent impairment of synaptic plasticity by Abeta oligomers: implications for novel therapeutic strategy in Alzheimer's disease. Neurobiol Dis. 2016;91: 124-31.

59. Provenzano $\mathrm{L}$, et al. Cellular prion protein $(\operatorname{PrPC})$ in the development of Merlin-deficient tumours. Oncogene. 2017;

60. Megra BW, Eugenin EA, Berman JW. The role of shed PrPc in the Neuropathogenesis of HIV infection. J Immunol. 2017;199(1):224-32.

61. Puig B, et al. N-glycans and glycosylphosphatidylinositol-anchor act on polarized sorting of mouse $\operatorname{PrP}(C)$ in Madin-Darby canine kidney cells. PLoS One. 2011;6(9):e24624.

62. Winklhofer KF, et al. Inhibition of complex glycosylation increases the formation of PrPsc. Traffic. 2003;4(5):313-22.

63. Taraboulos A, et al. Cholesterol depletion and modification of $\mathrm{COOH}$ terminal targeting sequence of the prion protein inhibit formation of the scrapie isoform. J Cell Biol. 1995:129(1):121-32.

64. Kascsak RJ, et al. Mouse polyclonal and monoclonal antibody to scrapie associated fibril proteins. J Virol. 1987:61(12):3688-93.

65. Bueler $\mathrm{H}$, et al. Normal development and behaviour of mice lacking the neuronal cell-surface PrP protein. Nature. 1992:356(6370):577-82.

66. Fischer $M$, et al. Prion protein (PrP) with amino-proximal deletions restoring susceptibility of PrP knockout mice to scrapie. EMBO J. 1996;15(6):1255-64.

67. Prox, J., et al., Postnatal disruption of the disintegrin/metalloproteinase ADAM10 in brain causes epileptic seizures, learning deficits, altered spine morphology, and defective synaptic functions. J Neurosci, 2013. 33(32): p. 12915-12928, 12928a.

68. Postina R, et al. A disintegrin-metalloproteinase prevents amyloid plaque formation and hippocampal defects in an Alzheimer disease mouse model. J Clin Invest. 2004:113(10):1456-64

69. Uchiyama K, et al. Prions amplify through degradation of the VPS10P sorting receptor sortilin. PLoS Pathog. 2017;13(6):e1006470.

70. Jackson WS, et al. Spontaneous generation of prion infectivity in fatal familial insomnia knockin mice. Neuron. 2009:63(4):438-50.

71. Hartmann D, et al. The disintegrin/metalloprotease ADAM 10 is essential for notch signalling but not for alpha-secretase activity in fibroblasts. Hum Mol Genet. 2002;11(21):2615-24.

72. Falker $\mathrm{C}$, et al. Exosomal cellular prion protein drives fibrillization of amyloid beta and counteracts amyloid beta-mediated neurotoxicity. J Neurochem. 2016;137(1):88-100.

73. Polymenidou $\mathrm{M}$, et al. The POM monoclonals: a comprehensive set of antibodies to non-overlapping prion protein epitopes. PLoS One. 2008;3(12): e3872.

74. Supattapone $S$, et al. Identification of two prion protein regions that modify scrapie incubation time. J Virol. 2001;75(3):1408-13.

75. Holthoewer D, et al. Acitretin, an enhancer of alpha-secretase expression, crosses the blood-brain barrier and is not eliminated by P-glycoprotein. Neurodegener Dis. 2012;10(1-4):224-8.

76. Sathya $\mathrm{M}$, et al. Resveratrol intervenes cholesterol- and isoprenoid-mediated Amyloidogenic processing of AbetaPP in familial Alzheimer's disease. J Alzheimers Dis. 2017:60(s1):S3-S23.

77. Hundhausen $C$, et al. The disintegrin-like metalloproteinase ADAM10 is involved in constitutive cleavage of $\mathrm{CX} 3 \mathrm{CL} 1$ (fractalkine) and regulates CX3CL1-mediated cell-cell adhesion. Blood. 2003;102(4):1186-95.

78. Liang J, Kong Q. Alpha-cleavage of cellular prion protein. Prion. 2012;6(5): 453-60. 
79. Walmsley AR, et al. Alpha-cleavage of the prion protein occurs in a late compartment of the secretory pathway and is independent of lipid rafts. Mol Cell Neurosci. 2009;40(2):242-8.

80. Korth C, Kaneko K, Prusiner SB. Expression of unglycosylated mutated prion protein facilitates $\operatorname{PrP}(\mathrm{Sc})$ formation in neuroblastoma cells infected with different prion strains. J Gen Virol. 2000;81(Pt 10):2555-63.

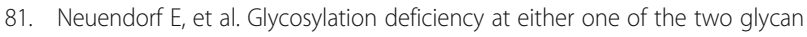
attachment sites of cellular prion protein preserves susceptibility to bovine spongiform encephalopathy and scrapie infections. J Biol Chem. 2004; 279(51):53306-16.

82. Katorcha $\mathrm{E}$, et al. Sialylation of prion protein controls the rate of prion amplification, the cross-species barrier, the ratio of PrPSc glycoform and prion infectivity. PLoS Pathog. 2014;10(9):e1004366.

83. Wiseman FK, et al. The glycosylation status of PrPC is a key factor in determining transmissible spongiform encephalopathy transmission between species. J Virol. 2015;89(9):4738-47.

84. Shyng SL, Huber MT, Harris DA. A prion protein cycles between the cel surface and an endocytic compartment in cultured neuroblastoma cells. J Biol Chem. 1993;268(21):15922-8

85. Sunyach $\mathrm{C}$, et al. The mechanism of internalization of glycosylphosphatidylinositol-anchored prion protein. EMBO J. 2003;22(14): 3591-601.

86. Nunziante M, Gilch S, Schatzl HM. Essential role of the prion protein N terminus in subcellular trafficking and half-life of cellular prion protein. J Biol Chem. 2003;278(6):3726-34.

87. Saftig P, Lichtenthaler SF. The alpha secretase ADAM10: a metalloprotease with multiple functions in the brain. Prog Neurobiol. 2015;

88. Madore N, et al. Functionally different GPI proteins are organized in different domains on the neuronal surface. EMBO J. 1999;18(24):6917-26.

89. Rambold AS, et al. Stress-protective signalling of prion protein is corrupted by scrapie prions. EMBO J. 2008;27(14):1974-84.

90. Fevrier B, et al. Cells release prions in association with exosomes. Proc Natl Acad Sci U S A. 2004;101(26):9683-8.

91. Wik $L$, et al. Separate mechanisms act concurrently to shed and release the prion protein from the cell. Prion. 2012;6(5):498-509.

92. Harris DA, et al. Processing of a cellular prion protein: identification of $\mathrm{N}$ and C-terminal cleavage sites. Biochemistry. 1993;32(4):1009-16.

93. Borchelt DR, et al. Release of the cellular prion protein from cultured cells after loss of its glycoinositol phospholipid anchor. Glycobiology. 1993;3(4): 319-29.

94. Chen SG, et al. Truncated forms of the human prion protein in normal brain and in prion diseases. J Biol Chem. 1995:270(32):19173-80.

95. Janes PW, et al. Adam meets Eph: an ADAM substrate recognition module acts as a molecular switch for ephrin cleavage in trans. Cell. 2005;123(2): 291-304.

96. Clement $A B$, et al. Effects of neuron-specific ADAM10 modulation in an in vivo model of acute excitotoxic stress. Neuroscience. 2008;152(2):459-68.

97. Suh J, et al. ADAM10 missense mutations potentiate beta-amyloid accumulation by impairing prodomain chaperone function. Neuron. 2013; 80(2):385-401.

98. Slack BE, Ma LK, Seah CC. Constitutive shedding of the amyloid precursor protein ectodomain is up-regulated by tumour necrosis factor-alpha converting enzyme. Biochem J. 2001;357(Pt 3):787-94.

99. Allinson TM, et al. ADAMs family members as amyloid precursor protein alpha-secretases. J Neurosci Res. 2003:74(3):342-52.

100. Endres K, et al. Shedding of the amyloid precursor protein-like protein APLP2 by disintegrin-metalloproteinases. FEBS J. 2005;272(22):5808-20.

101. Vincent B, Checler F. Alpha-secretase in Alzheimer's disease and beyond: mechanistic, regulation and function in the shedding of membrane proteins. Curr Alzheimer Res. 2012;9(2):140-56.

102. Chesebro B, et al. Fatal transmissible amyloid encephalopathy: a new type of prion disease associated with lack of prion protein membrane anchoring PLoS Pathog. 2010;6(3):e1000800.

103. Stohr J, et al. Spontaneous generation of anchorless prions in transgenic mice. Proc Natl Acad Sci U S A. 2011;108(52):21223-8.

104. Rangel A, et al. Distinct patterns of spread of prion infection in brains of mice expressing anchorless or anchored forms of prion protein. Acta Neuropathol Commun. 2014;2:8.

105. Harris B, Pereira I, Parkin E. Targeting ADAM10 to lipid rafts in neuroblastoma SH-SY5Y cells impairs amyloidogenic processing of the amyloid precursor protein. Brain Res. 2009;1296:203-15.

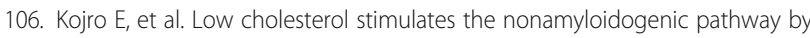
its effect on the alpha-secretase ADAM 10. Proc Natl Acad Sci U S A. 2001; 98(10):5815-20

107. Seipold L, Saftig P. The emerging role of Tetraspanins in the proteolytic processing of the amyloid precursor protein. Front Mol Neurosci. 2016;9:149.

108. Matthews $A L$, et al. Regulation of a disintegrin and metalloproteinase (ADAM) family sheddases ADAM10 and ADAM17: the emerging role of tetraspanins and rhomboids. Platelets. 2016:1-9.

109. Saint-Pol J, et al. Regulation of the trafficking and the function of the metalloprotease ADAM10 by tetraspanins. Biochem Soc Trans. 2017;45(4): 937-44

110. Morris RJ, Parkyn CJ, Jen A. Traffic of prion protein between different compartments on the neuronal surface, and the propagation of prion disease. FEBS Lett. 2006;580(23):5565-71.

111. Taylor DR, Hooper NM. The low-density lipoprotein receptor-related protein 1 (LRP1) mediates the endocytosis of the cellular prion protein. Biochem J. 2007:402(1):17-23.

112. Beland $M$, Roucou $X$. The prion protein unstructured $N$-terminal region is a broad-spectrum molecular sensor with diverse and contrasting potential functions. J Neurochem. 2012;120(6):853-68.

113. Dias MV, et al. PRNP/prion protein regulates the secretion of exosomes modulating CAV1/caveolin-1-suppressed autophagy. Autophagy. 2016; 12(11):2113-28.

114. Wetzel S, Seipold L, Saftig P. The metalloproteinase ADAM10: a useful therapeutic target? Biochim Biophys Acta. 2017;

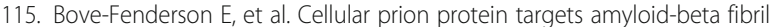
ends via its C-terminal domain to prevent elongation. J Biol Chem. 2017;

116. Wang J, et al. Treatment of SMB-S15 cells with resveratrol efficiently removes the $\operatorname{PrP}(\mathrm{Sc})$ accumulation in vitro and prion infectivity in vivo. Mol Neurobiol. 2016;53(8):5367-76.

117. Muller UC, Deller T, Korte M. Not just amyloid: physiological functions of the amyloid precursor protein family. Nat Rev Neurosci. 2017;18(5):281-98.

118. Crawford $\mathrm{HC}$, et al. ADAM10 as a therapeutic target for cancer and inflammation. Curr Pharm Des. 2009;15(20):2288-99.

119. Atapattu $L$, et al. An activated form of ADAM10 is tumor selective and regulates cancer stem-like cells and tumor growth. J Exp Med. 2016;213(9): 1741-57.

120. Bakkebo MK, et al. The cellular prion protein: a player in immunological quiescence. Front Immunol. 2015:6:450.

121. Wu GR, et al. Prion protein is required for tumor necrosis factor alpha (TNFalpha)-triggered nuclear factor kappa B (NF-kappaB) signaling and cytokine production. J Biol Chem. 2017;

122. Martin-Lanneree $S$, et al. $\operatorname{PrP}(\mathrm{C})$ from stem cells to cancer. Front Cell Dev Biol. 2014:2:55.

123. Santos TG, Lopes MH, Martins VR. Targeting prion protein interactions in cancer. Prion. 2015:9(3):165-73.

124. Yang $X$, et al. Prion protein family contributes to tumorigenesis via multiple pathways. Adv Exp Med Biol. 2017:1018:207-24.

\section{Submit your next manuscript to BioMed Central and we will help you at every step:}

- We accept pre-submission inquiries

- Our selector tool helps you to find the most relevant journal

- We provide round the clock customer support

- Convenient online submission

- Thorough peer review

- Inclusion in PubMed and all major indexing services

- Maximum visibility for your research

Submit your manuscript at www.biomedcentral.com/submit 